Portland State University

PDXScholar

Spring 6-7-2016

\title{
Stellar Works: Searching for the Lives of Women in Science
}

Jennifer Elizabeth Woodman

Portland State University

Follow this and additional works at: https://pdxscholar.library.pdx.edu/open_access_etds

Part of the History of Science, Technology, and Medicine Commons, Nonfiction Commons, and the Women's History Commons

Let us know how access to this document benefits you.

\section{Recommended Citation}

Woodman, Jennifer Elizabeth, "Stellar Works: Searching for the Lives of Women in Science" (2016). Dissertations and Theses. Paper 3030.

https://doi.org/10.15760/etd.3025

This Thesis is brought to you for free and open access. It has been accepted for inclusion in Dissertations and Theses by an authorized administrator of PDXScholar. Please contact us if we can make this document more accessible: pdxscholar@pdx.edu. 


\title{
Stellar Works:
}

Searching for the Lives of Women in Science

$$
\text { by }
$$

Jennifer Elizabeth Woodman

A thesis submitted in partial fulfillment of the requirements for the degree of

\author{
Master of Fine Arts \\ in \\ Creative Writing
}

Thesis Committee:

Paul Collins, Chair

Michael McGregor

Cynthia Lou Coleman

Portland State University

2016 


\begin{abstract}
While women have had a profound impact in the world of science, they struggle to gain an equal foothold in many science, technology, engineering, and mathematics (STEM) fields today. This has led to considerable public and private sector efforts to recruit women into these arenas. In order to understand how schools and nonprofits engage today's young women in STEM studies, this account includes time spent both in high school science classrooms and with ChickTech - a Portland-based organization that works to provide a pathway into tech careers for high school-aged girls.

A historical perspective reveals that modern women aren't treading into completely uncharted territory, in spite of the current disparity of representation in today's STEM arenas. This perspective is offered via an examination of the lives of a group of extraordinary women who worked in astronomy at Harvard College Observatory from the late 1800s into the 1960s. While several noteworthy women are discussed, the focus here is on Cecilia Payne, the first person to earn a Ph.D. in astronomy at Harvard, and one of the 20 $0^{\text {th }}$ century's greatest astronomers. A great many people have never heard of her ... yet.
\end{abstract}




\section{Dedication}

For my parents, who made loving words and language possible.

For David, whose kindness, love, and strength are infinite.

For Fiona, who will always be the brightest star in my universe. 


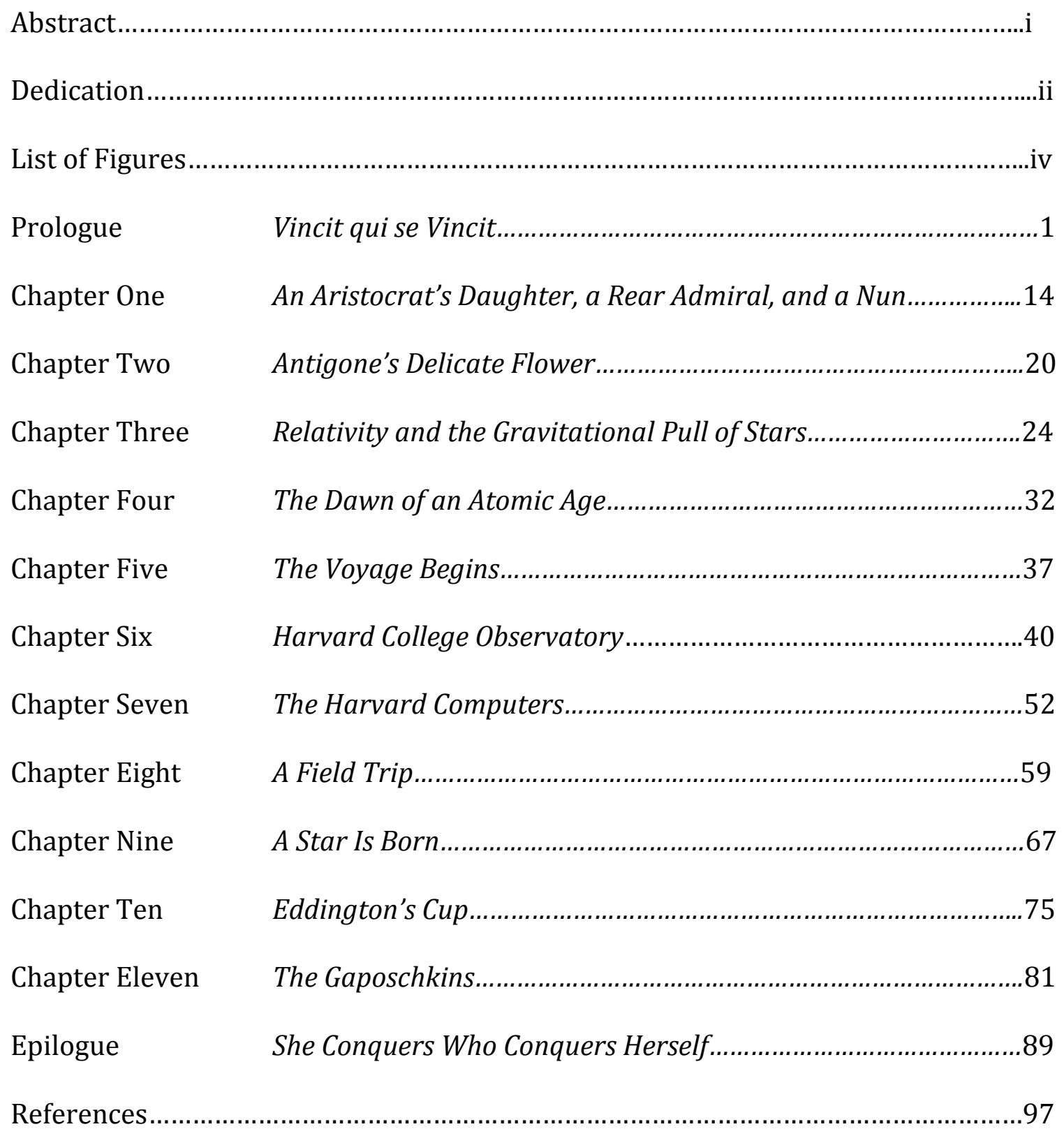




\section{List of Figures}

1 A photograph of a plate at Harvard College Observatory (HCO).......................1

2 Scientific apparatus at St. Mary's Academy for Girls, Portland, Oregon .............4

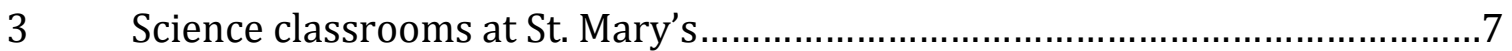

$4 \quad$ A bowling ball and ramp at St. Mary's......................................................11

$5 \quad$ Vines on a wall at Harvard in Cambridge, Mass.............................................14

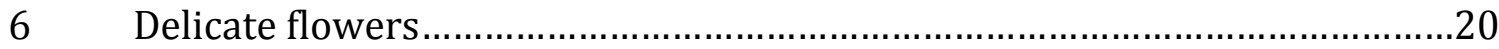

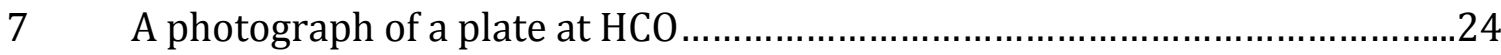

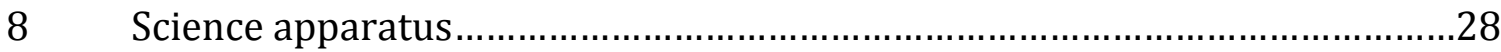

9 Photograph of a sketches for Annie J Cannon Prize, Harvard Archives...........32

10 One of the gates to Harvard's campus, Cambridge, Mass................................37

11 HCO Great Refractor Rotunda ................................................................40

12 A photograph of a plate of the moon taken in 1901 at HCO ...........................46

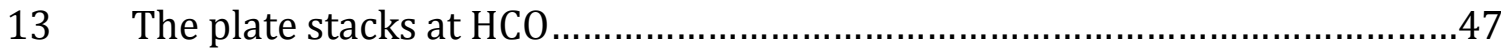

14 The dome of the Great Refractor at HCO

15 The seat apparatus for the Great Refractor at HCO ......................................51

16 Pickering's bust in the stairwell to the dome at HCO ....................................52

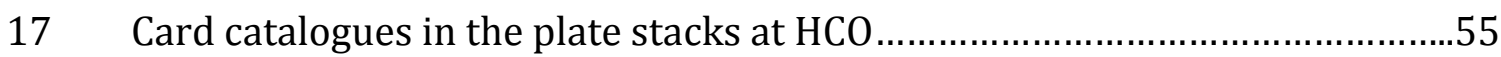

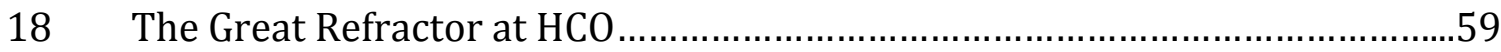

19 A photograph of Annie Jump Cannon's daily diaries, Harvard Archives.........60

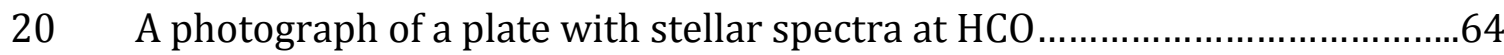

21 A photograph of a picture of Cecilia Payne at HCO ......................................67

22 A photograph of a plate with magnified stellar spectra at HCO ......................69

$23 \quad$ Slide catalogue at HCO ...........................................................................

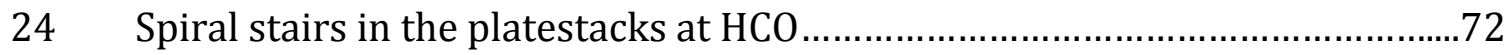

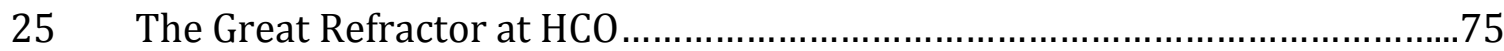

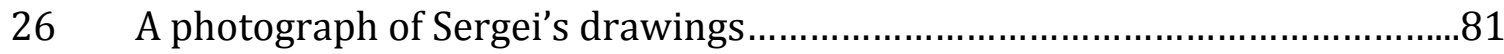

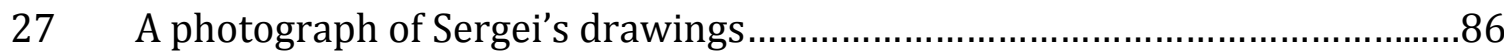

28 A photograph of Sergei's sketch of Cecilia's profile..........................................87

29 A photograph of a negative of Halley's Comet..............................................9

30 A student works on building a robot at ChickTech High School.....................93

$31 \quad$ Philadelphia High School for Girls insignia....................................................95

With the exception of Figure 31, all photographs were taken by the author. 


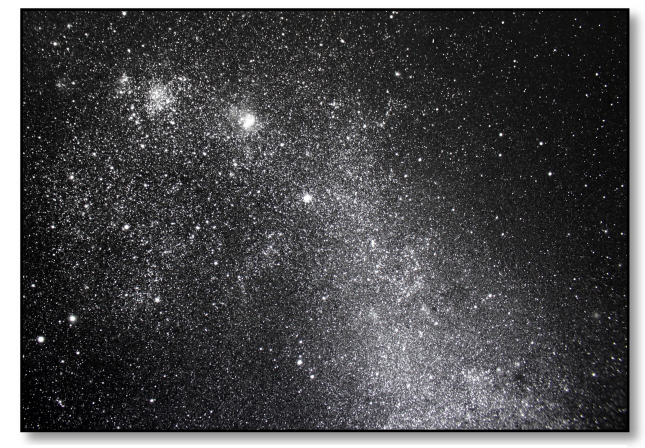

Figure 1: A photograph of a plate at Harvard College Observatory (HCO)

housing for a gamma ray and neutron detector destined for space, or an astrophysicist attempting to calculate the rate at which the universe is expanding. Think of a computer programmer sitting alone at a laptop writing code that will track and prevent the spread of infectious diseases using our cellphone data.

How did these scientists get to where they are in life?

Chances are, as young students they were encouraged in myriad ways. Maybe a middle school teacher challenged one of them to compete in a science fair, or to keep going when an experiment failed. Perhaps the young astrophysicist turned on the TV and saw the dawn of the space age and imagined a future where traveling to distant stars was possible. Maybe the coder was great at math in high school and a kindly teacher said, "You should think about a career in computer engineering."

By high school, these students probably had some confidence in their abilities, which led to advanced coursework, afterschool clubs, and summer programs. They possessed a confidence that comes from being seen and told you are good at this.

When you imagined those scientists a moment ago, maybe you pictured women filling those roles, but odds are those scientists were men, especially the 
engineer and the computer programmer. Strictly going by the numbers, women in 2 tech and engineering professions, after a brief spike during the 90's dot-com boom (and bust), are represented in about the same ratio as in the 1960s. It's pretty hard to imagine much else in American life that remains as it was 50 years ago.

In 2013, only 12 percent of engineers and 26 percent of computer professionals were women. The American Association of University Women looked at data from multiple sources and found that $4 / 5$ of the best STEM careers lie in these two disciplines. Women do have stronger representation in other STEM arenas, particularly health-related fields, but engineering and technology careers can be far more lucrative and offer a more diverse range of opportunities for employment. ${ }^{1}$ Many of the jobs available in tech and engineering don't require advanced degrees, so one can embark on a career where potential starting salaries average around $\$ 62,000$ without the hefty burden of additional student loan debt from graduate school. ${ }^{2}$

Equal representation also saves time and money when designing new, innovative systems, and when women aren't in the room some pretty big oversights are likely to occur. When the first voice-recognition programs were being designed, the developers calibrated them to male voices; the unintended result was that the programs literally couldn't recognize female voices. This is illustrated in a rather amusing thread in the Tesla Motors forums, where car owners can troubleshoot

\footnotetext{
${ }^{1}$ According to U.S. Department of Labor's Bureau of Labor Statistics, the median annual income for a computer professional is $\$ 79,420$ and $\$ 75,780$ for an engineer.

2 According to the U.S. Department of Labor, in 2013, out of 47,384 bachelor's degrees awarded for computer sciences, 8,611 went to women; among engineering majors women received 17,270 out of 98,540 bachelor's degrees.
} 
problems with their fancy, software-laden vehicles. In 2013, one Tesla owner writes, "As a female engineer myself, I'm familiar with the gender ratios on the design teams, so I understand first hand why these systems are better at recognizing male voices." She describes her issue and compares it to similar problems with her last car, a BMW. The seemingly small problem illustrates a larger issue. These types of technologies are often brainstormed and iterated in high end products. Then, they go on to be widely used as the technology becomes more affordable and accessible in other important ways like assistive technologies for people with physical impairments.

If the image of frustrated women yelling at their high-end automobiles in order to cue up the latest hit from Adele doesn't do it for you, consider how dangerous design oversights can be. Early airbags in automobiles were designed around the dimensions of adult male bodies - with the result that women and children died. Katherine Shaver, reporting for the Washington Post, notes that women and children are far more likely to suffer more serious injuries in a car accident, because smaller bodies aren't able to withstand the tremendous forces of a crash. It wasn't until 2003 that the federal government required manufacturers to use shorter female-sized crash dummies in some testing; now, the size of an average female dummy is 4'11" and 108 pounds. ${ }^{3}$

Clearly, there are valid reasons to eliminate barriers for entry into these professions. Just in case you aren't convinced yet, here's one more: engineering and

\footnotetext{
${ }^{3}$ According to the Centers for Disease Control and Prevention the average height and weight of an American woman is and 5'3" and 166.2 pounds; Shaver explains that the smaller-than-average female crash test dummy also doubles as a 12-year-old child.
} 
tech are realms where job growth is projected to be exponential in the coming

years. There are approximately 3.6 million computer jobs; by 2024, U.S. Department of Labor predicts 13 percent growth or an additional half million jobs. If our graduation rates continue as they are today, the U.S. may only be able to fill about 30 percent of those spots. Today's high school students could graduate from college, and unlike previous graduates over the last twenty years, they might be looking at unprecedented opportunities - if they possess the right stuff. But, how does one go about equipping young girls for this bright future?

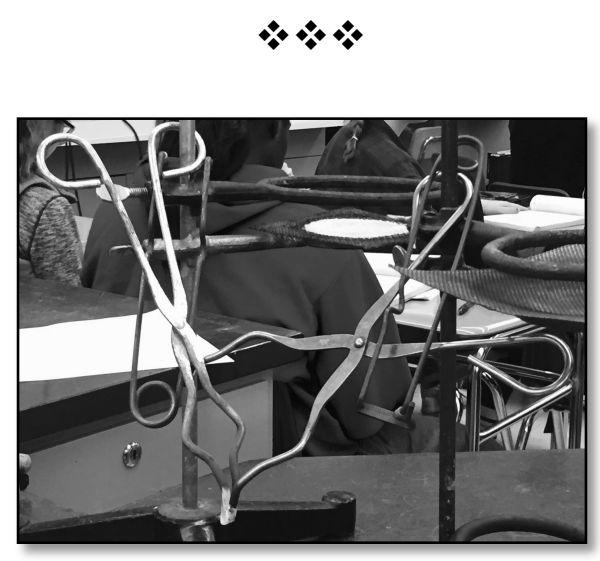

Figure 2: Scientific apparatus at St. Mary's Academy for Girls, Portland, Oregon

I've returned to high school - to St. Mary's Academy for Girls, a private Catholic school wedged in amongst the high-rises, crisscrossing light rail lines, and bustling traffic of downtown Portland, Oregon. The building feels clean and new, even though it was constructed in 1970. The shininess of it all is completely foreign to this veteran of Philadelphia's public schools (where decay is endemic in even the best places); here, multi-million dollar donors keep this place freshly painted and bubbling with an energy that is unique to teenaged girls in a boyless environment. 
A smiling, trim woman with a blond bob stands in the middle of the lobby, 5 armed with a clipboard. She greets the students as they pour in the front doors and course like arterial flow to the left, right, and into stairwells bound for other levels. "Okay girls, have a good day," she sweetly commands. Parents trickle in, apparently for chaperone duty, and converge around her. Eventually, she starts issuing directions like, "Pick up at 1:55." The parents nod and continue to shuffle around the lobby, uncomfortably checking their phones almost as frequently as the girls who flow past them.

A bell rings, and everyone vanishes like mist.

Another bell sounds, and the cheeriest voice I have ever heard bellows out over the loudspeaker, “Happy National Train Your Brain Day! Interested in architecture? Join the science club at lunch!" Each sentence ends on that upward note signifying to the listener that the speaker is, without a doubt, an American teenaged girl.

There's a plug for the school play, which is opening this week. The Second Cheeriest voice says, "Seniors, your Josten's orders are due!" and adds something about honors societies and an AP field trip.

My mind wanders as I think about my own class ring, which had an amethyst stone and my school's emblem etched on the side: a large oak tree under a banner that read vincit qui se vincit. I went to an all-girls school, and in lieu of a sports mascot, we had the tree of knowledge with a Latin motto that translates to: she 
conquers who conquers herself. ${ }^{4}$ Suffice it to say that even after 25 years, the convivial atmosphere and feeling of sisterhood at this little academy is shockingly familiar.

Cheeriest Voice \#1 concludes the announcements with, "Have a perspicacious day, St. Mary's!" A lone custodial worker pushes a trashcan and a cleaning cart down the hall as a smiling teacher briskly shuffles in the other direction.

Within an hour of being back at high school, I've learned that Uggs are still popular, skinny jeans will never go away, and it is apparently okay to wear socks with sandals now, but they do need to be the right kind of sandals, which is to say they need to be Birkenstocks. I've no idea who Sebastian is, but apparently for him, there are: No. Freaking. Words. Loving Simon and Isabelle is also something for which there can be no shame..$^{5}$ Dying one's hair outrageous shades of blue is no longer a sign of rebellion, rather it seems to signify conformity based on the number of blue-hued ponytails I see bouncing down these halls. The difference between a veteran and a less experienced teacher is obvious based on: the order of the room, the speed with which instructions are followed, and the overall tidiness of the actual teacher-person.

\footnotetext{
4 The Philadelphia High School for Girls, founded in 1848, is the last all girls public school in the United States.

5 I believe these are characters in a popular series written by Cassandra Clare, The Moral Instruments; like other young adult bestsellers, there are vampires and werewolves involved.
} 


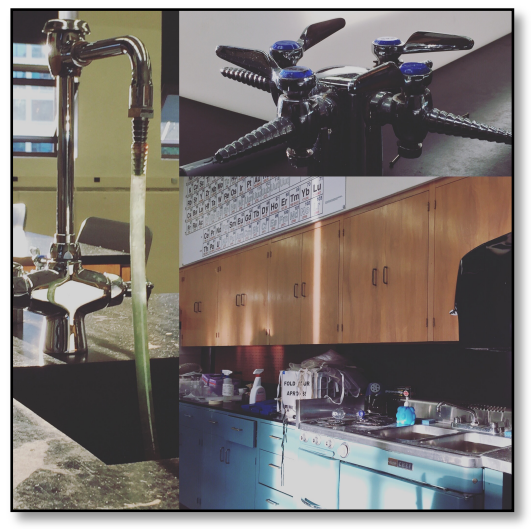

Figure 3: Science classrooms at St. Mary's

I sit at the back of Julia's biology class while another day's morning announcements are wrapped up by Cheeriest Voice \#1: "Have a supercalifragilistic day St Mary's!"

Julia gets her students started on the morning's project, which is to work independently on hormone reports that will be handed in the following day. "Finished projects need to be a minimum 2 pages, at least 2 pages," she says to a collective groan. She then directs anyone who has already finished their paper early to move on to test prep by checking out hyperlinks to virtual pig dissections. Not surprisingly, no one starts test prep.

The windows are open, and the building rumbles every time the Max train goes by: ka-chunk, ka-chunk and an electric whir followed by the return of humming and occasionally honking city traffic. The right wall is lined with kitchen-like cabinets, a stovetop with three electric burners, and a fridge. A faucet drips rhythmically. Above this, my eye follows the line along the bottom of a long poster of 
the periodic table and lands on a crucifix affixed to the wall by the door reminding 8 me of the Catholic Church's long and mostly positive relationship with science. ${ }^{6}$

As the hour wears on, it's clear that a few of the girls in the back aren't working on their projects anymore. Whispers are getting louder and they look happier than one would be while talking about estrogen or thyroxin. Julia speaks with individual students at the front of the room, "Ok, what is your hormone?" The girl meekly replies, "Melatonin" - the uncertainty in her voice making her answer seem more of a question. Julia says, "OK, Pub Med is the database I suggested. You don't have to use it but..." She goes off on a wonderful riff on the peer review process and how it relates to science. This particular interaction makes me feel all warm and fuzzy imagining how far ahead this student will be on her first day at university where freshmen typically don't come pre-equipped with a working knowledge of how the peer review and scientific process actually works. ${ }^{7}$

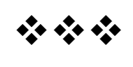

Moe Daschell, short for Maureen, is head of the science department. A petite woman, somewhere in that indistinguishable fiftysomething age, her face is framed with short auburn curls that look as if they possess a will entirely independent of

\footnotetext{
${ }^{6}$ Sorry Galileo!

${ }^{7}$ For the last four years, I have been the recipient of a scholarship and graduate teaching assistantship that requires mentoring freshmen and sophomores via my university's general education program. I have spent a great deal of that time teaching students about peer review, scientific process, and academic discourse. I can't speak to what happens at other universities, but at a state school with a large population of first generation college students (many from high poverty high schools) this is a very challenging subject for many students to master.
} 
hers. Smiling at me and scanning the room for potential problems, she lean-sits on 9 the edge of her desk and we have a lovely conversation about science, educating young girls, and contemporary pedagogical practices. In the middle of this conversation, Moe firmly admonishes me to get rid of my gum, as "this is a chemistry classroom;" she resumes our talk as if nothing happened. To say I complied quickly would be an understatement. It is probably quite obvious by now that both she and her science classroom are very, very tidy.

In Moe's classroom students conduct a chemistry lab experiment where they need to calculate the mass and volume of various elements suspended in water. Moe says, "After you take your measurements, decant the liquid ... Wait, who can tell me what decanting means?"8

Once the students are set up and working in their groups, I learn that at St. Mary's, freshmen start with physics; sophomore students take chemistry, and juniors, biology. Moe explains that since biology is much more focused on the molecular side of things these days, students do better when they start with the more observable sciences, which is reversed from what was thought best decades ago. She rattles off the names of schools in the region that have rejected this notion because, she suspects, veteran physics teachers don't want to teach freshman after so many years spent with more mature juniors and seniors.

At St. Mary's, there is also an emphasis placed on critical thinking. With each lab experiment, the girls start with completely wild and uneducated guesses. When they complete their measurements, they compare their wild guesses to the actual

${ }^{8}$ I resist the urge to raise my hand and offer an explanation of how to decant a fine bottle of aged wine. 
results, and on a third try with a slightly different experiment they'll begin with 10 educated guesses and see how close they can get to the actual results.

In a neighboring physics room, yellow boxes hang on heavy black cords over each of the two-person lab tables. The boxes are electrical outlets, but they lend the room the feeling that you are in an airplane that has just lost cabin pressure, causing those yellow plastic masks to drop from the ceiling. This classroom is more colorful and cheery than the others, and it isn't just the bright yellow boxes. On the wall to the left of the dry erase board is a sign written in neon markers; it reads - Our essential question: How do we find patterns in nature to predict the future and understand the past? The inside of the black window shades are adorned with colorful cutouts of stars and planets. There's another sign, a reminder that so many teachers love puns: Gear up to be a great student!

The class moves out to the hallway where a young teacher in a peach-colored skirt and soft grey cardigan carries long pieces of black PVC tubing, which are attached to each other making a sort of channel. She lays one end of the tubes on top of a binder to form a ramp. The girls stretch tape measures the full length of the hallway and line up to watch a bowling ball roll down the makeshift ramp. It lands with a soft thud that reverberates against the grey metal lockers; then, the ball smoothly rumbles and rolls up the white linoleum hall while designated timekeepers count out the seconds, “one...two...three...” Just like Moe's chemistry students, these girls have taken wild guesses about how far the bowling ball will roll, and they'll compare these results to what they observe, here in this hallway with floors that are buffed to perfection. 


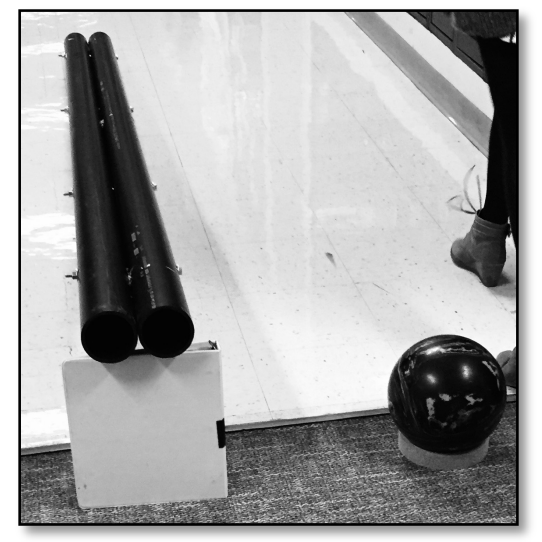

Figure 4: A bowling ball and ramp at St. Mary's

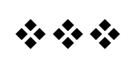

At St. Mary's, it's obvious that there is a concerted effort underway to give these girls the skills they'll ultimately need to compete in an increasingly STEMobsessed world. The school recently purchased additional land and the administration hopes to build a new state of the art facility for science, computer, and mathematics programs. In addition to the required courses, the school offers advanced scientific research methods, advanced placement coursework, and computer classes. There's a Tech Club where the girls can work on a 3D printer, build robots, and explore career options in science and tech; the club is led in part by Alexis Lund, who teaches algebra and history.

Alexis's class is doing research in the library when the bell goes off for an earthquake drill. The students quietly get up and move to the rectangular tables, which they promptly crawl under. I freeze and wonder if it is okay to pretend like I'm not really here, but someone gives me a stern librarian eye and I join the girls under tables that really ought to be a few inches taller.

"Ladies, no talking," says Alexis. 
A single strand of long, blond hair hangs from the corner of an empty oak 12 chair in front of me; it flutters in the air-conditioned breeze.

"Ladies, it is really sad that you can't be quiet," she admonishes again.

I spare a few moments for all the things I find really sad right now, including the painful crick forming in my neck, and decide that girls quietly whispering and giggling through an earthquake drill isn't that sad. Several girls nap. Alexis, crouched next to me, issues another exaggerated "shhhhhhh."

When the drill is over, she seems eager to talk with an adult, rather than shushing young girls ad nauseam. When I ask about her thoughts on why girls disengage from science and math, it's as if I've uncorked a bottle, the contents of which have been under pressure for just a tad too long. She echoes familiar sentiments about why girls don't always thrive in STEM: gender bias in classrooms, media portrayal of women, and a lack of role models.

"There are always the stereotypes on shows like The Big Bang Theory where three nerdy guys have ditzy girls as friends," she says.

For Alexis, who is young enough to recall her high school and college experiences with a proximal clarity, there were a fair amount of women in her college math and science classes, but only if those classes were geared towards teaching. When she moved on to her upper division advanced coursework, she was often the only woman in the room.

With her students, she makes a point of talking about the types of careers where math skills are crucial for success, particularly engineering. “It didn't even occur to me to study engineering because that wasn't talked about," she says. Today, 
Alexis imagines that she might have gone on to be an engineer if only someone had encouraged her. In high school, she was tutoring others in math and felt comfortable, so she chose the subject as her major in college. She says this with a shrug, as if it no longer matters, but something in her expression hints that residual feelings linger.

Alexis has kept in touch with former students who went into engineering programs. When she learned that they often felt isolated and under a great deal of pressure, she decided to make a concerted effort to start talking about what college will be like for these young women in casual ways - without, hopefully, discouraging them.

Perhaps one way to encourage these young women to pursue science and tech careers is to show them that they won't be the first to do so. While many of the girls who choose to enter a STEM field will probably experience what so many women have shared with me - the frustration that comes with being the only woman in the room - they need to know that they will not be alone.

They will be standing on the shoulders of some pretty amazing ladies. 


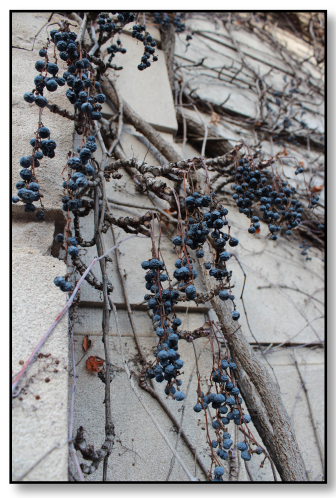

Figure 5: Vines on a wall at Harvard in Cambridge, Mass

\title{
Chapter One
}

\section{An Aristocrat's Daughter, a Rear Admiral,}

\author{
and a Nun
}

If you were to take a wild guess about the evolution of computing and engineering based on evidence observed in modern times, you might expect to find that women have never been able to break into these fields. Maybe women are just now overcoming barriers that have simply existed since the first lever was pulled or the first line of code was written. This logic would make sense in 2016 when women have made decent, albeit staggered, headway in so many other areas; it would seem improbable for tides to have completely reversed, setting women back in a field so vital to our modern, digitallydriven lives.

But what about the first computer programmer, who happened to be a woman born in 1815? The Countess Ada Lovelace, daughter of Lord Byron, was a STEM pioneer. Apparently, there was no love lost between her parents, who separated shortly after her birth; Ada's mother insisted that her daughter study science and mathematics out of fear that she would become a poet like her temperamental and brooding father - obsessed with dark nights and raven tresses.

In 1834, Ada met Charles Babbage, who was trying to invent a "calculating engine" that could predict certain outcomes and make decisions based on those predictions. She helped this fellow and ultimately published an article in which she 
discussed a future machine that could write music, draft artwork, and serve

science. Then, she wrote a roadmap for how the engine could calculate a sequence of rational numbers called Bernoulli numbers; today, Ada's work on this is considered to be the very first computer program. When I think about this, I can't help but pause and run my fingers slowly over the smooth, flat keys of my laptop and wonder - what would Ada think of this little miracle?

Of course, one $19^{\text {th }}$ century aristocrat does not a pattern make. What if we add a woman who served in the United States Navy? Rear Admiral Grace Hopper, dubbed Amazing Grace, is certainly owed space in our little list. In the 1940s, Grace became the one of a small group of elite computer programmers to work on the first large-scale computer called Mark I: “An impressive beast. She was fifty-one feet long, eight feet high, and five feet deep," she said. In the 1960s, Amazing Grace wrote a computer language, COBOL, that streamlined the Navy's programs, and she developed the concept of cleaning up a computer. She decided to name this process "debugging" after she opened up the behemoth Mark I to figure out why it wasn't working properly and found a moth.

After Hopper came Sister Mary Kenneth Keller. She was the first woman to receive a Ph.D. in computer science. In the 1960s, Sister Mary wrote the computer language BASIC, which essentially opened up the floodgates for computer programming. Prior to its creation, only mathematicians and scientists with advanced degrees could write programs or software. Using BASIC, anyone armed with this language could create new programs for computers, and many did. 
Over the last 100 or so years, women have made invaluable contributions 16 to the field of computer science. ${ }^{9}$ Much of this work was due to World War II, when women were recruited to perform complex mathematical computations for codebreaking operations and ballistics calculations. Women were employed, quite literally, as human computers. As progress marched on, women could be found in the basements of companies like IBM, punching holes in cards that were used to store early programs. Women like Margaret Hamilton who, while working for NASA, wrote the code that allowed our astronauts to safely leave the Earth's orbit, land on the moon, and then return home. When stacked, the code listings that comprised the software for the Apollo computers towered over Hamilton's 5-foot frame.

This raises an obvious question: why would a field that was once somewhat integrated become male-dominated over just a few years? Research has provided clues, but no definitive answers. Some argue that the professionalization of the field led to more restrictive, male-centric hiring and recruiting in the 60's and 70's. Others point to the evolution of the home computer, which fostered a gaming culture that was and continues to be the nearly exclusive domain of boys. One 2010 study points to the personality and aptitude tests companies used when hiring; the researcher argued that these "tests led to a feedback cycle in which companies hired 'antisocial, mathematically inclined males,' perpetuating the belief that programmers should be antisocial, mathematically inclined males."

\footnotetext{
${ }^{9}$ Lest you think I've merely combed the annals of history for a few odd examples, we could, thanks to the folks at the Ada Project, also add these outstanding ladies, in no particular order, to our list: Edith Clark, Margaret R. Fox, Hedy Lamarr (yes, that Hedy Lamarr), Kay McNulty, Frances Spence, Jean Bartik, Frances Elizabeth Holberton, Ruth Teitelbaum, Marlyn Meltzer, Adele Goldstine, Betty Snyder, Betty Jennings, Fran Bilas, Katherine Johnson, and many, many more.
} 
These challenges are not new either. In some regards women's entry into 17 the world of computing mirrors their entry into another field: astronomy. Before women were employed to perform the mathematic equations to support the war efforts and advance the space race in the U.S., women were making an indelible mark in the ever-evolving fields of astronomy and astrophysics by working as human computers - counting and calculating the position of stars.

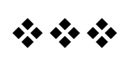

A few years before Woolf wrote $A$ Room of One's Own and lectured on women in fiction at Newnham College, another woman attended Newnham and found herself, like Woolf, isolated and alone in her pursuits: Cecilia Payne. Cecilia's successes and struggles offer a view of the ways in which women toiled away hoping to answer important questions and to reveal something unknown about the universe. Cecilia, and others like her, helped to make room for the women who did and will follow.

In 1925, she became the first person to earn a Ph.D. in astronomy at Harvard. ${ }^{10}$ Her dissertation was widely celebrated by her mentors and peers at the time, and 45 years after it was published, Otto Struve wrote that her work was "the

\footnotetext{
${ }^{10}$ She was not the first woman to earn a Ph.D. in astronomy; that honor goes to Margetta Palmer for her study of a comet in 1894 at Yale.
} 
most brilliant Ph.D. thesis ever written in astronomy."11 Cecilia was one of the $20^{\text {th }}$ century's greatest astronomers and few people know who she was.

I found myself drawn to Cecilia because she struggled to be heard. Her thesis work challenged conventional beliefs about the stars and their composition; this led her advisors to insist that she include a disclaimer in her dissertation about her findings that helium and hydrogen were abundant; it read: "almost certainly not real." As I began developing my own thesis, this particular bit of information reverberated a little louder in my mind and I couldn't let it go. I imagined devoting so much time and energy to a topic - having the work diminished in such a dismissive manner seemed utterly horrifying.

Whatever initially drew me to Cecilia, in the end it was the combination of her tremendous successes and her, at times, larger-than-life flaws that really captivated me. She was brilliant and incredibly well read, but she was also, by her own admission, quite jealous of her peers and struggled with certain aspects of being a wife and mother. When her first child was born, she brought him to work with her and used her desk drawer as a crib so she could keep working. Cecilia's final graduate student Owen Gingerich ${ }^{12}$ writes of rumors about her fiery relationship with her husband: "graduate students assumed that their two offices

\footnotetext{
${ }^{11}$ Also thought to be one of the great astronomers of the $20^{\text {th }}$ century, Struve was a prolific scholar with over 900 scientific publications; he also headed up some of the most prestigious observatories in the U.S. including Yerkes and the National Radio Astronomy Observatory.

12 Owen Gingerich is professor emeritus of astronomy and the history of science at Harvard; he is an extraordinary scholar in his own right. His lectures at Harvard are the stuff of legends as he was known to go to great lengths to demonstrate a point. He once used a fire extinguisher to propel himself out of the classroom in order to teach his students about Newton's Third Law of Motion. He is one of the world's leading scholars on Copernicus and Galileo, and has been awarded several medals and countless honors. Owen helped the Polish government locate Copernicus's remains, an act that earned him a special spot at the funeral of Copernicus.
} 
were widely separated to keep the stormy personalities from asserting

themselves too conspicuously." Somehow these nuances made her humanity shine through for me in a way that a perfect portrait of a saint could not. Her strengths and weaknesses also help reveal something about the efforts inherent in becoming a scientist when the odds are stacked against you. 


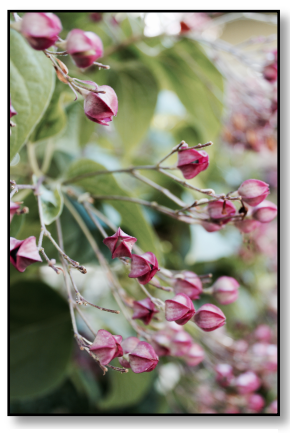

Figure 6: Delicate flowers

\section{Chapter Two}

\section{Antigone's Delicate Flower}

During the months of June and July, there's a flower that

blooms near Cecilia's childhood home in Wendover, England. It

nestles in the tall grasses and stands up to the strong winds that blow across open spaces in the springtime. The outer petals look like a purple star, and the inner blossom forms a soft furry lobe with vivid yellow and dark burgundy, which happens to look exactly like the body of a bumblebee. The flower is a Bee orchid, or ophrys apifera. The orchid looks like a bee and puts off a scent that lures hapless bees in for what botanist Fred Rumsey of the Natural History Museum refers to as "pseudo-copulation."13

When she was eight, Cecilia stumbled upon this delicate flower in the orchard and immediately knew what it was. She felt her heart leap with excitement when she remembered how her mother had described the way some flowers look like insects. She "was dazzled by a flash of recognition." Later in life, Cecilia traced her path back to this event - her first plant identification - and knew this was the moment she became a scientist.

She eloquently wrote about this scene in parallel with the moment she first realized that planetary nebula are actually expanding and not rotating, as was once

\footnotetext{
${ }^{13}$ Since there aren't a great many bees in England's damp and chilly climate, the orchid also selfpollinates.
} 
thought. To her, these two distinct events, separated by decades of life and experience, were "moments of ecstasy."

Cecilia was born on May 10, 1900 to Emma and Edward Payne. Her father was a lawyer, musician, and amateur scholar. When she was four, he was found dead, face down in the waters of a local canal; as it was common knowledge that he had heart problems, it was assumed that he died of a heart attack. She idolized him when he was alive, and spent many subsequent years reading his books, studying in the family library, and learning to play his violin, which was given to her when he died. Even some 70 years later in her autobiography, she was unable to elaborate much on his death beyond saying, "I shall say nothing of that traumatic experience, which I remember only too well ... For the rest of my childhood I felt I was not like other children, for I had two fathers in heaven."

His untimely death made making ends meet difficult for Cecilia's mother; a young woman left to raise three children on her own had few options in those days. Yet, despite the challenges, her mother surrounded the children with art and literature, starting with Homer's Odyssey, which Cecilia remembered hearing aloud while sitting on her mother's knee. While her immediate family possessed little wealth, they did possess an intellectual heritage that included notable connections like a librarian from the Berlin Royal Library, the famed geologist Charles Lyell, and an aunt who worked with Charles Darwin.

The family frequented the theater, and she recalls being surrounded by her mother's paintings. At some point in her childhood, they inherited a large collection of books and Cecilia spent a great deal of time reading and studying on her own. 
“Our house was full of books, not only my Father's library, but legacies from many 22 forebears - Latin, Greek, French, German, Spanish, Icelandic books, waiting to be explored," she wrote.

At this point it might be worth mentioning that Cecilia herself was no delicate flower. She put off no scent that attracted hapless boys to her side, and by age 13, she started to grow facial hair. It's hard not to feel a sympathetic tightening of the chest and imagine the horror she must have felt when the doctor told her there was nothing to be done about it.

She wept uncontrollably. But he comforted her and said, "Never mind Cecilia, you've got brains. Make something of them." And, in what I am coming to see as typical fashion for Cecilia, she doesn't linger on this discomfort, and simply notes that it "stiffened my resolve to become a scientist."

Cecilia's daughter Katherine writes that her mother "cared little for feminine niceties." Cecilia never wore makeup or dressed in a very feminine way and, at 5'10", was quite tall for a woman at that time. In grainy black and white photographs that accompany anything written about her, she's always looking off to the side with a sort of smirk that reminds me of the Mona Lisa. She isn't exactly smiling, or frowning, but she does look rather serious. With her hair swept across her forehead and always either short or pulled back, she could easily have stood in for a Renaissance portrait or sculpture of her favorite Greek heroine, Antigone.

With the exception of her brother and father, Cecilia was rarely around boys or adult men. She wrote, "Women dominate my background: memory recalls greatgreat aunts, great aunts and an aunt. Few of them married. There is hardly an uncle 
in the picture." Her lack of exposure and her discomfort with her own physical appearance offer partial explanations for why she was so terribly shy. This shyness was probably not aided by the treatment she received from many of the men she did encounter as she moved through her schooling and later in her professional life. ${ }^{14}$

Cecilia dedicated a large portion of her autobiography to her early education and saw this time in her life as pivotal in her development as a scientist - from the memorization and recitation of her early education to the emphasis on the classics in what we would consider today as her high school years. Each of these studies gave her tools that would aid her future scientific endeavors like a keen eye for observation and a flair for writing well.

Her frequent complaint was the fact that she had to fight to be taught science and math. One of her schools did not offer science for the younger students, and she felt that the other school thought it a waste to teach women these subjects as the young female students were "destined for a social world." But, Cecilia persisted and won a scholarship to Newnham College, fulfilling her dream of attending Cambridge. ${ }^{15}$ There, she was able to study with some of the greatest scientists of the day, including Sir Arthur Eddington - the director of the Cambridge Observatory.

\footnotetext{
14 Virginia Trimble writes in an introduction to the Dyer's Hand, "A recent letter from my thesis advisor recalls an incident where a group of astronomers were discussing a suitable gift for [Cecilia] in some significant birthday, and the winner (at least on the laugh meter) was 'a shaving machine' ... It is by no means the most unpleasant one I heard in preparing this introduction."

${ }^{15}$ In order to study at Cambridge University in her day, one had to be admitted to a specific college; Newnham College was one of two women's colleges in Cambridge University.
} 


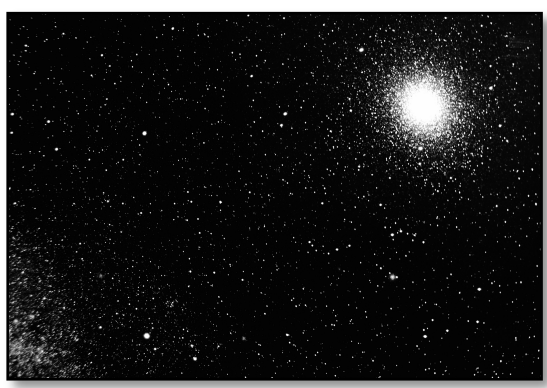

Figure 7: A photograph of a plate at $\mathrm{HCO}$
Chapter Three

Relativity

And the Gravitational Pull of Stars

There are certain facts we take for granted.

Gravity exists. In a right triangle, $\mathrm{A}^{2}+\mathrm{B}^{2}=\mathrm{C}^{2}$. The Earth rotates around the sun, and force equals mass times acceleration. Whether we truly understand these ideas or not, for all of these commonly held truths, there was a time when they simply weren't. There is always some point wherein this knowledge remains unfound, or too new to really make sense. Then, a paradigm shift occurs, like tectonic plates pulling apart the ocean floor, releasing volumes of magma and creating new earth new knowledge replaces the old. New ideas change how we view ourselves in relation to each other and the universe we inhabit.

Since the $17^{\text {th }}$ century, Sir Isaac Newton's Laws reliably predicted the outcome of observations about the movement of stars and planets across the night sky with at least one exception: Mercury. Over the centuries following Newton's work, it appeared that Mercury's orbit around the sun was moving just a tiny bit faster in one spot, gaining an extra degree every 8400 years. No explanations for this anomaly succeeded in explaining it until 1905, when Einstein introduced the first of two papers that would eventually become the General Theory of Relativity; the second paper was published in 1916. Up until that point $\mathrm{E}=\mathrm{MC}^{2}$ meant nothing. Our understanding of movement and time was constrained by our understanding of these phenomena on Earth. It turns out we weren't paying enough attention to our 
own movement as we hurtled through space aboard planet Earth. Einstein believed, correctly, that space and time were relative to the speed and location of the person making the observation. He also theorized that the gravitational pull of a body could warp or bend light traveling through space, which would account for Mercury's anomaly.

Arthur Eddington learned of Einstein's new work during World War I, and became the first advocate for the theory in England. In 1919, Eddington along with his colleague, Frank Dyson, embarked on a dual expedition to prove Einstein's theory correct. Eddington sailed to Africa, Dyson to Brazil. They hoped to observe a solar eclipse, which would block the sun's bright light just long enough to make light from a large cluster of stars, the Hyades, passing through the sun's gravitational field visible here on Earth. If there were no clouds in the sky, the two astronomers should be able to photograph and measure the stars' positions and determine if the light was bending at all - and they did. When Eddington announced their findings, Einstein became famous around the world, almost overnight. ${ }^{16}$

While Cecilia read widely in other scientific disciplines, up until this point, she had been immersed in what she describes as utterly uninspired botany courses at Newnham College. When she first learned about a new theory, which stated that all motion was relative, she wondered: relative to what? She wrote, "The solid ground failed beneath my feet...I had my first sense of the Cosmos." On December 2, 1919, a schoolmate became ill and offered her a ticket to see Eddington give a lecture about relativity at Cambridge.

\footnotetext{
16 Although several accounts reveal that Einstein was rather nonplussed about confirmation of what he already knew with certainty to be true.
} 
Several accounts of the event recount how scores of men gathered in a line 26 that wrapped halfway around Thomas Neville's Great Court at Trinity College. They may not have noticed Cecilia bundled up - protected from a squally winter night. A westerly wind blew storms in from Iceland, making the day and evening rainy and overcast. Was she the only woman in the crowd? Maybe. Although it is hard to imagine her blending in, given her stature, regardless of any desire she had to hide in plain sight.

Inside, the stoic portraits of Francis Bacon, Sir Isaac Newton, and Lord Tennyson looked down on the attendees, and the sound of people fidgeting and settling in their wooden chairs bounced off of the huge hammer beamed ceiling in the medieval hall. The smell of wet wool lingered in the air. Cecilia sat enthralled as she listened to this young, dark-haired Quaker walk the audience through the basic concepts of Einstein's theory. The knowledge he shared changed everything, but he spoke with ease, as if he were describing some familiar every-day occurrence.

Eddington expressed a desire to explain the theory and their subsequent experiment without using complex mathematic and scientific explanations. He saw himself as a sort of translator for the common man, or woman as it turns out. He wrote, "The mind is not content to leave scientific Truth in a dry husk of mathematical symbols, and demands that it shall be alloyed with familiar images." Eddington wanted everyone to understand the importance of this work that he believed was a "revolution of thought in physical science."

When Cecilia returned home that evening, she found she was able to write down the lecture, verbatim. She wasn't able to sleep that night, or the two that 
followed. "The result was a complete transformation of my world picture," she wrote. Cecilia was done with biology, a path she originally chose partly by default because her school didn't offer physical science courses and because her Aunt Dora, a plant biologist, had inspired her. She would dedicate her energies to studying physics. She wasn't permitted to switch to astronomy, which was situated in the mathematics department and would have required starting from the very beginning again, but she attended every lecture she could find and read voraciously on the subject.

The British system is and was fairly different than the U.S. - students could pick which lectures they chose to attend - or, as you can also imagine, chose not to attend. At the end of the year, students took general examinations in what we would now think of as their major. It would make sense for students to go to lectures in their own area of study, and not dabble in other complex subjects simply for the fun of it.

Unless that student were to be Cecilia - who, at the age of 12, rebelled against the lack of science classes for younger students in her school by reading Newton's Principia on her own and memorizing the Linnaean taxonomy. ${ }^{17}$ By the age of 15 , she'd taught herself German, calculus, and geometry because these subjects weren't taught to girls and she thought they might be important to her scientific interests. In her free time between these Herculean and entirely self-imposed tasks, she used to sneak into the science classroom used by the upper grades just to gaze on the apparati of science - the beakers and flasks, lengths of tubing and bits of wire, small

${ }^{17}$ Remember kingdom, phylum, and class from your high school biology? 
jars of chemical elements. A hodge-podge of materials just out of her reach: "Here 28 were the warp and woof of the world, a world that was later to expand into a Universe ... I had yet to realize that the heavenly bodies were within my reach."

What a wonderful nuisance she must have been to those school administrators and instructors - rooted in their traditions, pedagogy, and rules about what proper English girls needed.

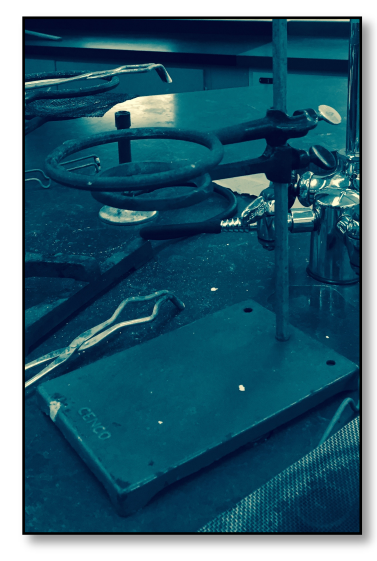

Figure 8: Science apparatus

\section{$* *$}

One night, when the Cambridge Observatory was open to the public, Cecilia rode her bike to the building and promptly began peppering the dour man operating the telescope with questions. He fled his post and Cecilia took over telling onlookers what to watch for. She stood at the telescope with a young girl balanced on her hip and explained that they were seeing the Andromeda Spiral - the nearest neighbor to our own Milky Way galaxy.

She heard laughter, and turned to find Eddington standing behind her. The astronomy professor later told Cecilia that his assistant came at him in a panic 
asking for help because, he explained, “There's a woman out there asking questions!"

The two chatted. Cecilia described their interaction, writing "I blurted out that I should like to be an astronomer. Was it then or later that he made the reply that was to sustain me through many rebuffs? 'I can see no insuperable objection.'” Eddington recommended several texts, and was amused to discover she had already read them all. From there, she attended all of his lectures and those of several other notable astronomers and physicists of the time.

She was determined, and on a path.

Bored with her physics studies, Cecilia asked Eddington for some research to do on her own time. He gave her photographic plates of a cluster of stars and asked her to calculate their proper motion. This required learning how to reduce equations by least squares, which is a method of statistical regression that allows one to predict something unknown with data on hand. Being very Cecilia about the whole business, she marched over to the British Museum and read through the complete works of a fellow named Gauss, who is credited with inventing this particular statistical analysis in 1795 . She spoke of her adventure at the library: "They were in German, in enormous, fat volumes, probably the original edition. Probably I am the only surviving student that went all the way back to Gauss to learn how to do least squares." When she produced her finished work for Eddington, he was pleased enough to help her publish the paper, her first of many publications to come, in the Royal Astronomical Society. 
Back on the Newnham campus, she found an old observatory with a

telescope that was no longer functioning and undertook the task of restoring it to working order. Her friend, the astronomer and Ph.D. candidate L.J. Comrie, offered advice about repairs and hoped to inspire her observations with the gift of a book about variable stars ${ }^{18}$ written by Caroline Furness.

Comrie was Australian and just back from the war where he lost his leg and hearing; the two became good friends during her frequent visits to Eddington's observatory where he worked. "He was a very remarkable man - a very brilliant man of great courage," she said. Comrie would eventually go on to a prestigious posting in Her Majesty's Nautical Almanac Office where, after several years, he would be suspended for his obsession with mechanical computation, which was deemed rather unconventional at the time. Today he is considered a pioneer in early computing and advanced mathematics as well as astronomy. ${ }^{19}$

Cecilia described her pet-project telescope as "full of marks and rust and corruption," but she cleaned it up and learned how to oil the clock and get it running again. With this small instrument she began her own study of the stars, and even held public nights for others to learn and enjoy what she saw. She added a log near the telescope and wrote in very large letters in the front pages, "Whatever you do with this telescope, be sure to write it down in detail in the book and date your entry." While Cecilia's observatory is still there, the book has since disappeared. It's

\footnotetext{
18 Variable stars change in brightness periodically and were little understood at that time; Cecilia would go on to dedicate a large portion of her career to studying variable stars.

${ }^{19}$ Former student and astronomer Margaret Mayall mentions taking what she believes was the very first computer course offered for credit in the U.S. at Swarthmore; Comrie was her instructor.
} 
hard not to imagine a long list of names and dates indicating when others took

pleasure gazing at the stars after reading her own impressions of those early

observations: "I discovered the beauty of the planets - who can ever forget [her]

first sight of the moons of Jupiter and the rings of Saturn?"

Cecilia, thanks to her own persistence and Eddington's support, had "opened the doors of the heavens" - and she never looked back. 


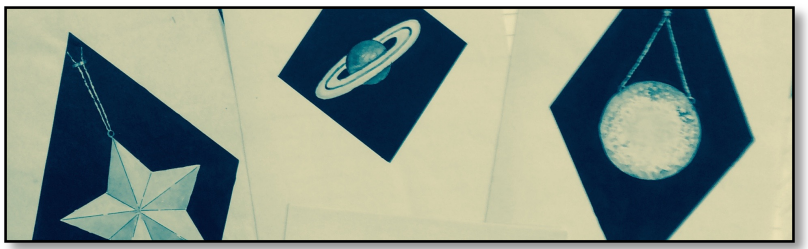

Figure 9: Photograph of a sketches for the first Annie J. Cannon Prize, Harvard Archives

By 1919 women were finally permitted to move around campus and attend classes without an escort, but they were required to sit in the very front row of the lecture hall. Men were not allowed to sit near women, so they filed in behind Cecilia. The instructor, Ernest Rutherford, is considered by many to be the father of nuclear physics, but he was not kind and fatherly to Cecilia in this particular series of advanced physics. At the beginning of each lecture, he would make a point of glaring directly at her, with pinched lips obscured by a salt and pepper mustache, and exclaim with his New Zealand accent, "Ladies...and Gentlemen." His greeting became a familiar and dreaded experience to her. Not surprisingly, the ritual caused all sorts of a ruckus with clapping and foot stomping, which made her desperately want to disappear. Many years later, even after decades as a professor at Harvard, she always preferred sitting in the back of any meeting or gathering. ${ }^{20}$

Throughout her life, she struggled with what she viewed as unjustified limitations forced upon her gender. It started when she was still in her nursery and realized that, in the eyes of others, her brother Humfry's adventures and education were more important than her own. She wrote, "It did not take me long to feel that I lived in a man's world." Her time at Cambridge was no different with characters like

\footnotetext{
${ }^{20}$ Rutherford may not have been deliberately trying to embarrass her, as he did have other female students over the years that recalled him quite fondly, but she was already terribly shy and this didn't help matters.
} 
Dr. Searle who actually believed female students disrupted "the magnetic equipment." According to Cecilia, he was known to admonish young women to take off their metal corsets. While many of her teachers represented some the great thinkers of that time, to say they weren't quite ready for women at the university would be a bit of an understatement.

Rutherford won a Nobel in chemistry in 1908, and later made significant advances in atomic theory, including uncovering the secrets of the half-lives of atomic elements. While Cecilia would go on to witness a great number of celestial discoveries, at Cambridge she had a (mandatory) front-row seat for the dawn of the atomic age, and access to this relatively new knowledge would play a very large part in her own astronomical discoveries in the years that followed. In addition to Rutherford, her professors and visiting lecturers included at least four Nobel laureates among which were the fellows who discovered the electron, the first subatomic particles, and the neutron.

Niels Bohr, a guest lecturer, revealed the structure of atoms for his Nobel. ${ }^{21}$ Bohr was Danish and Cecilia never understood his lectures because of his accent; she "for many years wondered what 'soup groups' were." In an oral history at the Niels Bohr Archive, she describes her astonishment when she finally put the pieces together and was able to figure out the $s-u$-b-groups on the periodic table of elements.

${ }^{21}$ Thus establishing a foundation for any recurring nightmares you may have of chemistry exams and the periodic table. 
A more intimidating undergraduate faculty would be hard to conjure, and 34 it isn't surprising that she should go on to do great works given the foundation that was laid during this time in her life.

But she wouldn't be able to do great works in England.

Women in England weren't allowed to actually receive degrees; rather, a woman was allowed to pay for what they referred to as the title of a degree. The honor came with a certificate, which stated the holder had fulfilled all of the requirements and passed all of the examinations for a degree. She was not permitted to write B.A. after her name; the title was ironically notated as "tit. B.A.". There was a great deal of debate at the time regarding education for women. Sylvia Boyd writes about how women were segregated at Cambridge and their battles for degrees: “This segregation symbolized a woman's position as an outsider. Outsiders have an uncomfortable time in establishment institutions, where the insiders do not hesitate to offend them; thus in 1921, after another attempt to allow women the "title" of a degree had gone down to defeat, some exultant male undergraduates used a porter's coal trolley to smash down the bronze Clough Memorial gates at Newnham College." It wouldn't be until 1948 that women's colleges were granted the same privileges as men's, including the right to more than just the title of a degree.

By her own account, Cecilia was fed up with being the only woman in her classes and knew that there was no future for her in England, where the only suitable pursuit would have been teaching. She came to this realization when 
Schoolmarm, a satirical poem that recreates the process of becoming:

Anxious, hurrying women

Always tired, And starved of life, Who teach children, Other women's And of love know nothing.

Thanks to Hamilton, it dawned rather dramatically on Cecilia that the life of a "school mistress" would have been "a fate worse than death."

Studying in the United States became a possibility thanks to Comrie's support. Knowing her options were limited in England, he took her to another astronomy lecture in London given by the newly appointed head of Harvard Observatory, Harlow Shapley. His lecture was, in her words, inspiring: "I was completely fascinated because for the first time I had a vision of the way in which astronomy conducts observations, [I] had seen the plates at Cambridge but they were - somehow they didn't seem alive." Cecilia marched up to Shapley at the end of his lecture and declared that she wanted to come and work for him.

The two corresponded and she received hearty recommendations from Eddington, Comrie, Searle, and several other teachers. In spite of old Dr. Searle's frustration with ladies' metal undergarments messing with the lab equipment, Searle wrote a lovely letter on her behalf, stating, "She is a thoroughly earnest student and very keen on her work." Eddington wrote about her dogged pursuit of knowledge, adding that she "possesses the valuable qualities of energy and enthusiasm in her work." Comrie wrote the most effusive of the recommendations: "I know of no lady in England who is more likely to be successful at Harvard than 
Miss Payne. There is this to be said about her (between ourselves) - I believe she 36 is the type of person who, given the opportunity, would devote her whole life to astronomy and that she would not want to run away after a few years training to get married."

Shapley was convinced; Cecilia was going to America. 


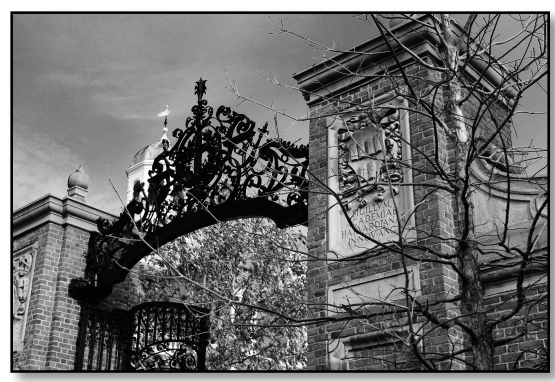

Chapter Five

Figure 10: One of the gates to

Harvard's campus, Cambridge, Mass

While Harvard had a prestigious observatory and many people working on astronomy, the previous director, Edward Charles Pickering, had focused solely on collecting data and viewed the observatory as a research facility, not a teaching institution. Shapley offered Cecilia enough of a stipend to begin her studies as the very first Ph.D. candidate in astronomy. With persistence she gathered the necessary funds for her big move: she wrote an essay on the Greek texts of the New Testament for which she won $£ 50$. With her winnings, she was able to purchase new clothes for her travels.

In September of 1923, Cecilia set sail for New York on the RMS Caronia, a British ocean liner that also served as a troop ship during World War I. ${ }^{22} \mathrm{Her}$ uneventful transatlantic crossing took just over three days, and gave her ample time to contemplate all she was leaving behind. Later, she would become an American citizen because she felt both duty-bound to be able to vote where she lived and also gratitude to a country that offered her the chance to be a scientist. But, no matter how much time passed, Cecilia would always long for England and the fragrant aroma of primroses, violets, and whitethorn; the sights and sounds of spring never

\footnotetext{
22 On the morning of April 14, 1912, the Caronia, traveling eastbound for Liverpool, delivered a warning to another ship on the Cunard Line: ice at 42 degrees north. The following morning, just after midnight, the Caronia transmitted news of the Titanic's distress call.
} 
left her imagination even though she found New England to be an utterly spring- 38 less place where icy cold winters turn to steaming hot summers in a "sudden burst."

The Coronia landed safely in New York, where Comrie waited to greet her.

He'd completed his doctoral work at Cambridge and had recently taken a position at Swarthmore College in Pennsylvania. The two toured New York before she boarded another boat bound for Boston, where Cecilia found a world and a life quite different than what she was accustomed to.

She described her first impressions, "Coming to Harvard was intoxicating. It was partly the ... New England climate in the fall, well, I found it physically intoxicating. I had never felt like that before."

The weather wasn't all that intoxicated Cecilia.

For the first time in her life, she was completely and utterly free to do as she chose, and being Cecilia, she chose to work. At Newnham, women had to be in their dorms for lights out at 11. "You were permitted a candle, but who can work by a candle?" she asked her interviewer between drags on her cigarette. ${ }^{23}$ At Radcliffe, the women's college connected to Harvard, she was free to come and go as she pleased and she did. It was not an uncommon occurrence for Cecilia to work through the night because she was no longer in a world of wondering about stars and the universe in the abstract.

The stars were now completely within her reach. At Harvard College Observatory she could actually lay her hands on the very objects she had only previously dreamt of, because of the most wonderful of modern inventions:

${ }^{23}$ Cecilia was a very heavy smoker. Owen Gingerich wrote, "I really learned what chain smoking was. A pack of cigarettes and a single match could get her through an entire period." 
photography. In 1880, thanks to Pickering, the observatory had started amassing 39

what would become the world's largest collection of photographs of the stars -

525,000 slices of the sky captured on the glass for all to see. ${ }^{24}$

\footnotetext{
${ }^{24}$ Anna Draper established the Henry Draper Memorial as a tribute to her husband in 1886. Anna wanted to help Pickering complete a catalog of all the stars in the sky. A physician by trade, her husband Henry was an avid amateur astronomer who pioneered early techniques for photographing stellar spectra. During his life, the couple waged an ambitious campaign to determine the composition of the stars via photography, so Pickering convinced the wealthy widow that the star catalog would be a fitting tribute to her husband. By 1949, after several expansions, the Henry Draper Catalog included 359,083 stars, and Draper's name has indeed lived on.
} 


\section{Chapter Six}

\section{Harvard College Observatory}

If you could magically erase the modern automobiles and electrical wires that crisscross overhead, the neighborhood surrounding the observatory might look much as it did by the time Cecilia arrived here. The crooked streets are lined with grand Queen Anne styled homes and large Georgian brick houses,

painted shutters adorning each of the many windows. A gentle

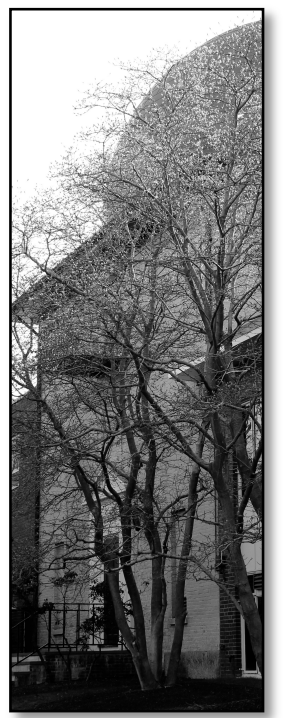

Figure 11: $\mathrm{HCO}$ Great Refractor Rotunda dusting of snow softens everything and makes it that much easier to imagine the sounds of horses clip clopping down the lane when the oldest of these houses first appeared.

Wander away from the Charles River on Brattle Street just as Cecilia would have done when she shared an apartment in a flatiron building on Mt. Auburn with fellow astronomer and friend, Francis Wright. Turn up Buckingham Place as it curves towards Concord Avenue. Be careful not to trip over the spots where ancient tree roots have pushed the bricks out of kilter, and you'll eventually come to the northwestern end of the observatory. It sits up on a hill, across from St. Peter's Catholic Church. A tall spire casts shadows over the parish playground where children run around the play structures like excited little atoms pinging to and fro. From down below, at street level, three domes sit atop several of the old buildings 
that make up this complex, each at different heights. They add a strange

symmetry to the buildings, which obviously date from different eras.

Today, most of the telescopes have been moved to locations far from city lights that pollute the night sky, but old sepia-toned photographs show how a crop of domes once lined up along the grounds like an ancient, but orderly dinosaur egg farm. These buildings, I learn, are the only structures in Cambridge that perfectly align with due east and west as a result of the old meridian telescopes that once topped the older structures. ${ }^{25}$

The observatory and surrounding buildings sit upon what was once Summer House Hill, now named Observatory Hill. The land was purchased by the university for $\$ 4100$ around 1843. Andrew Craigie, a surgeon during the Revolutionary War, originally owned the land; after the war he amassed a tremendous amount of wealth and property, which was eventually divided and subdivided amongst subsequent generations of his heirs. Just over six acres, this portion of the estate sat 50 feet above the surrounding area, which was largely undeveloped at the time. A 1931 Harvard Monograph notes that as there were "no electric lights and no street cars or heavy trucks, the situation was as favorable as could be desired."

As you wend your way up the driveway, you come to a large brick building with white trim; this is Building D. A white balustrade frames the roof and a double staircase with iron railing leads to the main entrance, adding to the grandeur of the

\footnotetext{
${ }^{25}$ Stephan P. Maran writes that a meridian is "the imaginary line from the zenith to the south point in the horizon. A star is best placed for observation when it's on the meridian." The zenith is the point directly above you as you look at the horizon straight ahead, forming a 90-degree angle with your sight line. Meridian telescopes were used to measure a star's movement across the local sky, so the telescopes were mounted in a fixed direction and the Earth's rotation brought the stars into view for data collection.
} 
structure. I've seen these steps many times in the old photos, although ivy once

crept up the facade. Whenever there was a meeting or gathering, the astronomers, including Cecilia, would line up along the stairs and fill in the space in front for a group portrait. She always seemed to be standing in the back row looking as if she'd rather be somewhere else.

The salt crunches under my feet as I mount the steps, and I can't help but feel a sense of awe as I push open the door. The feeling is somewhat dampened by the utterly ordinary handwritten signs adorning several of the doors in the hallway; the papers flap and flutter with the rush of January my arrival brings. The floors are carpeted, but the wood beneath creaks as people walk to and fro. To my left is the entrance to the plate stacks where I meet Alison Doane, curator of the plate archives.

She is ready for me with loads of materials and the enthusiasm of someone who has been working with these astronomical ephemera for many years. Fresh out of conservatory with training as a classical oboist, Alison needed a job and landed one at the observatory working in the plate stacks. "Did you make your own reeds?" she asks when I reveal that I too was an oboist in another life.

The previous curator saw something special in Alison, and pegged her as her predecessor early on. 33 years later, Alison is downright gleeful as she opens the cardboard box that contains the first items she has gathered to show me - a series of daguerreotypes of the moon from 1852. Each image is encased in a leather box that opens from the center of the lid to reveal the picture nestled in red velvet. The first image has several small, fuzzy moons, captured as the orb moved across the night 
sky. The second is crystal clear and displays the top half of a tiny moon rising out 43 of the darkness with its familiar craters visible. We move on from the daguerreotypes to the plates I have come here to see.

Before the invention of film, early photographers used glass. At Harvard (and other observatories) these glass plates were coated with a wet solution composed of "guncotton and potassium iodide in alcohol and ether," and then mounted onto a telescope to be exposed for minutes to hours, depending on the desired results. After the exposure was complete, a coating of an emulsion of silver salts converted the iodide to silver iodide and a positive or negative of the image could be developed, revealing a slice of the sky at a given date, time, and position. Over time, the chemical processes improved dramatically, making photography an integral component in the evolution of astronomy and astrophysics.

Alison stands the glass on the edge of the lighted viewing table that sits at a 45-degree angle in front of us; she slides the plate partially out of the worn envelope. Now she can view the pane without touching anything but the edges. She shows me how one side is shiny and the other is rather dull - the dull side is the side with the emulsion. She warns that you don't want to touch that part of the plate as the aging material can crumble and flake off. Now that she is certain which side is the top, she slides it carefully out of the envelope and onto the viewing table.

At first glance, it looks as if someone has captured, with perfect clarity, an image of the contents of a vacuum cleaner bag. She hands me a magnifying loupe and shows me how to adjust my position for a good view. I brace the side of my 
hand against the glass, as instructed, and situate my right eye at the loupe. Once 44 my eye adjusts, the fuzziness disappears and I'm looking at a dense cluster of stars.

She pulls out the next plate and situates it on the table for me. The glass has tiny purple writing on the non-emulsion side - N4774, N4662, N4711, and so on. One object is circled and "asteroid" is written in cursive next to the small speck of a dot. The front of the envelope contains all the relevant information - the date and time, length of exposure, the declination and right ascension. ${ }^{26}$ This particular plate was taken on March 20,1907. Williamina Fleming made these notations; she was the first curator of the plate collection.

We go through dozens of these plates, and I get the sense that Alison is building up to something. I can't imagine seeing anything more spectacular than a negative image of the Andromeda nebula sitting in a sea of white surrounded by tiny black pinpoints; I smile and think of Cecilia manning the telescope back at the Cambridge Observatory. Then, Alison reveals an absolutely perfect image of the moon, captured in 1901, with vivid lines emanating from the impact craters that actually create the illusion of movement within this moment frozen here on the glass for 115 years and counting.

I can't help but think: we are nothing.

We sit on a speck of dust in an infinite sea of other specks of dust. Yet, somehow we are aware of our nothingness and still we persist: we toil away in an effort to understand our infinitesimal place in this vast cosmos.

${ }^{26}$ Declination and right ascension are astronomical terms for position, comparable to longitude and latitude here on Earth. 
The ceiling is just low enough to make me feel taller than I am, and the

walls are pin-cushioned with memorabilia - photos of the human stars who worked here, notes, and newspaper clippings. Perched on a shelf is a worn and obviously loved stuffed toy - a rabbit with a pink sign hanging around its neck that identifies the critter as one Henrietta Leveret; a star dots the $i$.

"I just love puns," Alison says with a silly grin as she poses for a photo with the stuffed leveret nuzzled against her face.

Henrietta Leavitt was an astronomer who worked at the observatory from 1893 until her death in 1921 . Henrietta classified over 2400 variable stars, and specifically identified Cepheid Variables, which are stars that pulsate with temperature and diameter changes. ${ }^{27}$ She served as the second curator of the plate collection, after Williamina.

A few lines of poetry, written in black fountain pen on a scrap of yellowed paper, catch my eye. The words are attributed to Diana, a former archivist, from 1964:
Keyholes of light long dark corridors of time, open secrets yet unveiled to searching eye, rest on cool glass. Instants frozen In eternity.

\footnotetext{
${ }^{27}$ This discovery established what is called the "Period-luminosity relationship;" this relationship greatly aided astronomers in their efforts to measure distance in space, which helped improve our understanding of the size of the universe.
} 


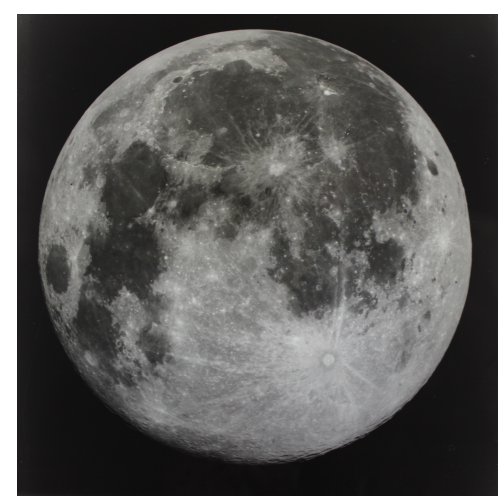

Figure 12: A photograph of a plate of the moon taken in 1901 at HCO

Behind us, rows of huge metal cabinets with creaky metal doors stand a little more than shoulder's distance apart; row after row of these cabinets fill three floors. Dark, military green and sturdy, these shelves contain the plate collection. At some point, there were fears that an earthquake would destroy the archive; the building is supported by a metal framework that is separate from the building's actual structure..$^{28}$

Alison struggles with an aging handle and opens the doors to reveal hundreds of yellowed sleeves identical to the ones we just perused, standing on their side like a prized record collection. She balances on her tiptoes and adjusts the angle and arrangement, explaining that careless workers occasionally don't line them up properly.

"It puts too much weight on the plates at the ends of the rows," she says with a grunt as she shifts things into the correct position.

\footnotetext{
${ }^{28}$ As an East Coast transplant to the West Coast, I was skeptical about the potential hazard in Massachusetts, but there have been several, including a rather large one in 1755 . The US Geological Survey notes, "On November 20,1755, the Boston Weekly News-Letter reported 'a most terrible Shock of an Earthquake: The conditions were so extreme as to wreck the Houses in this Town to such a degree that the Tops of many Chimnies, and some of them quite down to the Roofs, were thrown down....' This earthquake, with a magnitude of about 6.2, was centered off the coast of Cape Ann, MA."
} 
did not want limit the catalog to stars in just the northern hemisphere; in addition to plates from observatories elsewhere in the United States, these photographs were carefully ferried from observatories in Peru, South Africa, New Zealand, and Chile. The work that went into gathering this behemoth of a collection is awe-inspiring to envision. George Johnson writes about how one astronomer, Solon I. Bailey, packed plates into two wooden crates and carefully carried them down from the mountain in the Peruvian Andes, nicknamed Mount Harvard, "on muleback and across a suspension bridge." From there, the plates traveled on a train to Lima before making it on board a Boston-bound boat to Harvard. The same astronomer made that trip many times in order to deliver more than 2500 plates back to the observatory.

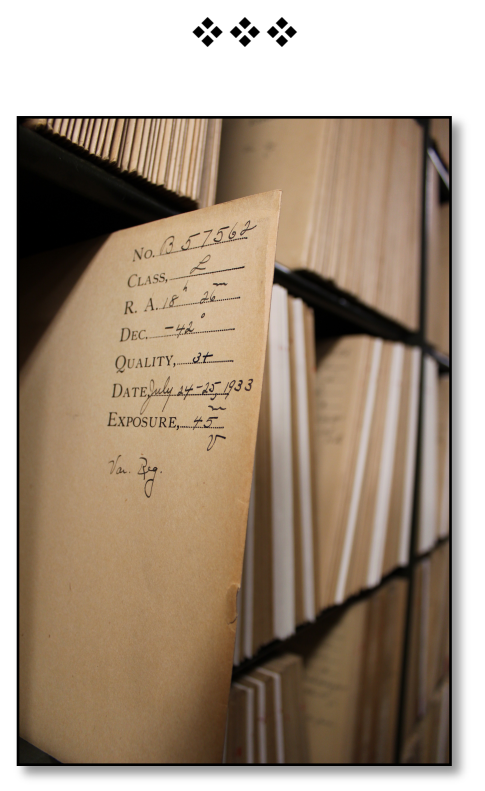

Figure 13: The plate stacks at HCO

Spiral staircases in the two outer corners of the buildings lead to the lower levels where one could work, seemingly for days, without interruption. We wind our way down and through the stacks to a closed door with a handwritten sign, "Do not 
enter - scanning in progress." Alison quickly makes a turn and we wend through

the subterranean space until we find the back way into the scanning room with a large clunky black machine and a young woman patiently toiling away. The glowing light, tendrils of cables, and low, rumbling hum make this machine feel as if it really ought to be housed in Dr. Who's TARDIS, but it is a scanner designed to digitize the plates.

According to Johnson, the collection weighs 165 tons and is the equivalent of a petabyte of data. ${ }^{29}$ Until several years ago, if something happened to this building, everything in it would be lost forever. Thanks to some prodding by Alison and her colleagues, and support from the National Science Foundation, Harvard has launched a massive effort to digitize the collection. The effort required designing a scanner that would work faster than standard high-end scanners, which wore out quickly; the machines couldn't handle the volume and took over 10 minutes per plate. ${ }^{30}$ Added to the challenges of funding, technology, and time was the issue of the physical layout of the building. The metal structure that is supposed to prevent damage during an earthquake includes steel beams every 4.5 feet, adding spatial requirements to large scanner's design.

Since 2004, they've been hard at work digitizing the plates, which will allow open access for all. These plates offer a unique opportunity to examine the sky in

\footnotetext{
${ }^{29}$ A petabyte is $10^{15}$ bytes of data, 1,000 terabytes or one million gigabytes. For the mathematically disinclined, some have conceptualized a petabyte as the contents of the US Library of Congress. One could actually lose quote a bit of time searching for comparisons to help one visualize this enormous amount of data. An iPod with petabyte of space could hold 209,715,100 songs, or a petabyte of average-length songs could play continually for 2000 years. Basically, it's a whole lot of data.

${ }^{30}$ At that pace, it would have take 50 years to scan the collection.
} 
100-year intervals, making it possible to learn about how the universe is changing 49 over time.

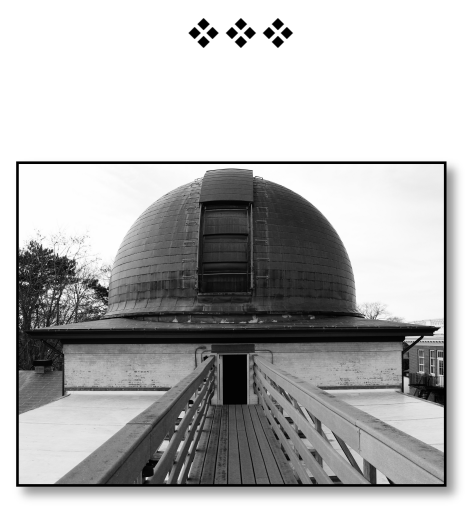

Figure 14: The dome of the Great Refractor at HCO

We make our way back up the winding corkscrew staircase and back out through the stacks to the cold, crisp January air. Alison and I head over to the observatory. There was once a gully that ran between the buildings, and a covered bridge eased passage, but today it is gone - we simply walk across the grass.

The whitewashed brick building is perfectly square with four steps leading up to the dark green wooden door, which is framed by an aedicule of ornately carved wood, painted white. The 30 -foot dome is covered in copper, oxidized to a lovely shade of green; it weighs 14 tons. The rotunda sits between two brick buildings, A and B, but originally, the observatory was flanked by a wooden structure that housed the astronomical plates. Considered to be both a firetrap and an earthquake hazard, the old buildings were eventually replaced by the existing structures and Building D was added in the 30's to house the ever-expanding collection of astronomical photographs.

Through the doorway, we find ourselves in a dimly lit round room lined with 
scientific student posters. The only object inside this space is the giant tower, or 50 pier, that holds the telescope on the floor above. The pier is made of Quincy granite, and it rests on a foundation that extends 26 feet below ground. Cecilia's daughter Katherine remembered the magic of playing hide and seek in this little catacomb when she and her two brothers were young.

Alison and I exit the room to the right and mount another set of circular steps, past a white marble bust of Pickering sitting in a recess along the curved wall, and into the telescope dome. While little to no serious observations take place here anymore, this telescope was once one of the most powerful in the world; it is called the Great Refractor. ${ }^{31}$

It's cold and smells of stone, brass polish, and dust. The seat apparatus is flanked by two curved ladders and a series of pulleys, ropes, and flywheels which are connected to what look like very long bicycle chains that allows the user to raise or lower the seat depending on where in the night sky you might want to point the telescope. The bench seat is large enough for two, with a wooden footrest; it looks like it could be part of an antique ski lift if it weren't covered with red canvas fabric. In the middle of the seat is a flat disk with a knob for steering. Spinning the disk would cause the entire seat and surrounding structure to rotate around the room or to elevate to a higher or lower position.

The telescope tubing is covered in mahogany and the workings are made of brass making it a thing of beauty to behold. The object glass was delivered and

\footnotetext{
${ }^{31}$ A refractor is a telescope that uses lenses and a reflector is a telescope that uses mirrors.
} 
installed on June 11, 1847. ${ }^{32}$ Harvard astronomer Solon I. Bailey wrote, "One can 51 readily imagine with what interest and even anxiety it was first turned toward the sky." The public was eager to see the results after lengthy fund raising campaigns for the most powerful and fine equipment available at the time. Expectations were high, and finely met. Many noteworthy discoveries were made using the Great Refractor, including Saturn's dark inner “Bond's Ring."

Cecilia would not have used this particular telescope regularly, because her work largely revolved around plates, but she likely sat here at some point, because it was here and it was magnificent. At Alison's invitation, I climb up into the seat and wonder what it might be like to have such a marvelous device to one's self in the quiet hours while others sleep - as if you are allowed, for a brief moment, to be alone with the stars. Sitting here, it is easy to see why Cecilia loved her work.

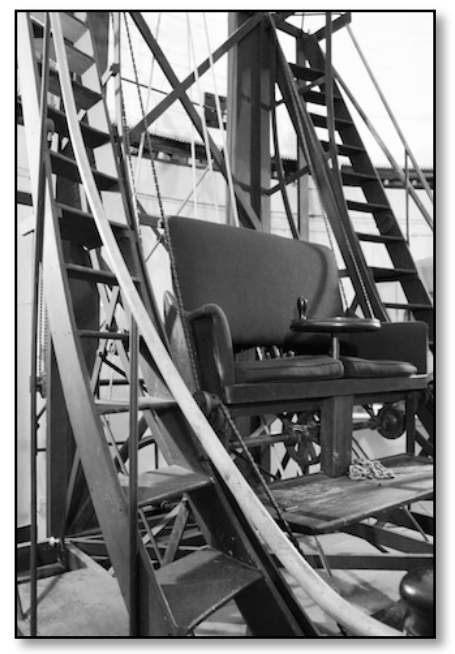

Figure 15: The seat apparatus for the Great Refractor at $\mathrm{HCO}$

\footnotetext{
32 The object glass or objective collects and focuses light to produce a clear real image.
} 


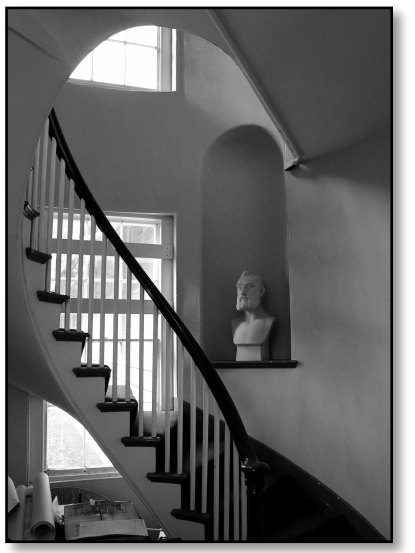

Figure 16: Pickering's bust in the stairwell to the dome at $\mathrm{HCO}$
Chapter Seven

\section{The Harvard Computers}

Cecilia was not the only star at the observatory. She may have been one of few females in her Cambridge classrooms, but at Harvard, thanks to the monumental nature of inventorying the heavens, Cecilia found herself in the company of a great number of incredibly smart ladies. In astronomy, the advent of photography opened up doors for women in new and exciting ways. Previously barred from nighttime observations in drafty, cold observatories in the company of men, women soon discovered that photography made astronomy, as Annie Jump Cannon would later write in 1929, "a daylight profession."

One popular version of the story of the Harvard Computers begins with Pickering in a tizzy about lazy graduate students who can't be bothered to write clearly or double-check their calculations. At the end of his rope, he stamps his foot and declares that his "Scotch maid" could do a better job than this silly boy. He fires the student and installs his maid Williamina Fleming as the head computer. Williamina does such a tremendous job that he hires nothing but women moving forward. These women are given the less-than-honorific collective nickname: Pickering's Harem.

The tale has a nice ring to it, because it taps into our intrinsic biases, which tell us that it really was a truly shocking surprise to discover women could or would do great work. And it has the gravity of random discovery that makes the whole 
history feel somehow magical - outside the realm of the ordinary. The problem is 53 this: the real story is even better.

In 1878, Williamina and her husband left Scotland and settled in Boston. By the next year, she was 23 , alone, and pregnant - her husband ran off, presumably in search of better things. Pickering was kind enough to offer her a job as his housemaid, but Williamina was quite bright and well educated. Back in Scotland, she had started student teaching in the local public school when she was just 14 . As the youngest of 14 children in a poor family, she taught to bring in extra money.

After serving as Pickering's maid for a year, her intelligence must have captured his attention, because he asked her to do some temporary work at the observatory. She did a fine job - so fine that she was hired officially in 1881, and within a year she was in charge of the day-to-day operations of the observatory, including editing the all the scholarly publications, and overseeing a team of women hired to support the ever-increasing demands of the Henry Draper Catalog. By 1898, the university appointed her as the first curator of the plate collection. She was the first woman to hold a corporation appointment at Harvard. ${ }^{33}$

As time progressed Williamina made many notable contributions and discoveries, including her system for measuring the magnitude or brightness of a star captured in a photograph; this system became an important tool for astronomers. On a plate in the collection, there was a cluster of stars marked B2312;

\footnotetext{
33 The first assistant professorship awarded to a woman at Harvard went to Alice Hamilton in 1919 in the university's school of medicine. John T. Bethell writes that it was not a widely celebrated event and she was not permitted to use the faculty lounge or to sit on the stage at commencement ceremonies. In 1956, Cecilia became the first woman promoted to full professor from within the university ranks.
} 
two years after the image had been captured, Williamina identified it as a nebula. 54 While the discovery was originally attributed to Pickering because he took the photograph, he amended the record and Williamina was given proper credit. Sue Nelson wrote, "Long after her death, when the Hubble Space Telescope unveiled the stunningly beautiful Horsehead Nebula in unprecedented detail, history had already noted that it was Williamina Fleming who had first identified the nebula's unusual shape."

Williamina described the daily routines and challenges of scientific research at great length in her diaries. She and twelve women would spend each day working with the photographic plates - "identification, examination, and measurement of them; reduction of these measurements and preparations of these results for the printer." In an age before mechanical computers, these human computers were expected to be at the observatory six days a week, seven hours a day, and they were granted a month of vacation after one year of employment. The women spent those days in a small library attached to the northern end of observatory, each focused on her portion of the burden of counting and studying all the stars the sky.

In an old photograph, dated 1891, the women sit in tight clusters around several large wooden tables; it looks as if there is hardly an inch to spare for movement, but no one appears to mind. The walls are covered with flowered wallpaper and the women wear long dark Victorian gowns with high collars. Williamina stands watch in the center of the photograph looking directly at the camera while all the computers sit with their heads bent, intent on their work. While Williamina occasionally bemoaned that oversight of the observatory pulled her 
away from her own scientific inquiries, she trusted the ladies to carry on with the 55 investigations while she trifled with the mundane.

Many of the women, with the exception of Williamina, never married and were still at the observatory by the time Cecilia arrived in 1923; she wrote of them in her autobiography. There was Miss Woods, who once served as Pickering's secretary and seemed to see herself as being of a different rank than the rest; she was "a stickler for protocol" and once scolded Cecilia for using Harvard stationary, something only important men could do. Miss Cushman was "a dignified galleon of a women with her masses of white hair" and had "never ridden in one of those newfangled automobiles" until Cecilia convinced her to give it a go when she purchased a little green Ford.

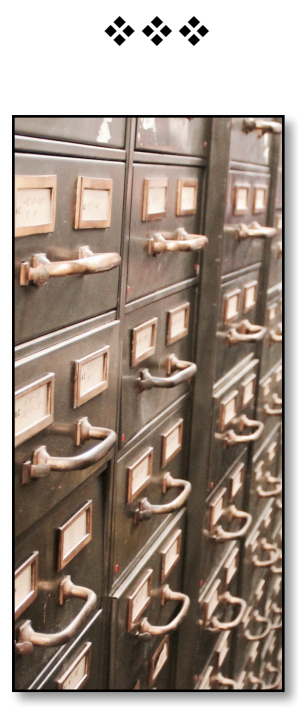

Figure 17: Card catalogues in the plate stacks at HCO

The subject of women and education remained controversial. Americans were coming around to the notion that it would be wise to have better educated teachers as public education was becoming widely available; since women dominated the teaching profession, this helped somewhat shift the view of 
serious arguments about the effect of education on women's health and

reproductive ability, but as the first women with college degrees married and had children, education became more and more acceptable for women."

Pickering and his successor Shapley were quite progressive for their time, as was Radcliffe, which began offering degrees to women in the $1889 .{ }^{34}$ Pickering supported women's suffrage and believed women should have access to advanced education. Just so long as it didn't interfere with the work he wanted them to perform - Antonia Maury, another famous Harvard Computer and niece of Henry and Anna Draper, told Cecilia that she always wished to learn calculus, but Pickering wouldn't allow it as it would supposedly interfere with her work. ${ }^{35}$

In addition to the director's progressive ideas about education, he was also quite pragmatic as well. Not only were the women employed at the observatory smart and capable of doing the work, they were also quite a bargain at 25 cents an hour. The position held a certain amount of prestige for the women, and factory work would have paid only 15 cents per hour. Women might earn more teaching, but that work wasn't as easy to find. Observatory jobs were in such demand that some women volunteered to work for free to prove their worth, but Williamina thought that might set a bad precedent.

\footnotetext{
34 While Harvard and Radcliffe were ahead of the curve in terms of educating women, Harvard President A. L. Lowell was not. He was so adamantly opposed to Radcliffe that he refused to sign diplomas; he thought Radcliffe was a drain on Harvard resources.

35 There may have been other problems - Pickering and Antonia were frequently at odds.
} 
In March of 1900 Williamina wrote in her journal, "I had some

conversation with the Director regarding women's salaries. He seems to think that no work is too much or too hard for me, no matter what the responsibility or how long the hours. But let me raise the question of salary and I am immediately told that I receive an excellent salary as women's salaries stand."

While Williamina adored Pickering and even named her son Edward Pickering Fleming, she fought with him about money often and confessed to wanting to give up at times. She knew he would have a hard time finding a man willing to work for less than what other male assistants at the university were making at the time, which was around $\$ 2500$ per year; Williamina made $\$ 1500$ and had to support her son, who was attending MIT by this time: "Does he ever think that I have a home to keep and a family to take care of as well as the men? But I suppose a woman has no claim to such comforts. And this is considered an enlightened age! ... I feel almost on the verge of breaking down," she lamented. In an age without most of the modern conveniences we now take for granted like the miraculous washing machine and dryer, it must have been exhausting to work all week and then spend her one day off cleaning bed linens and scrubbing floors. Her salary did not leave much room for hiring help and she was forced to take in boarders, usually one or two of the women from the observatory.

But Williamina did not break down; she persisted.

Her work led to international fame and recognition in the astronomical community. Over the course of her career, she discovered 10 novae, 52 nebulae, 310 
variable stars, and she classified over 10,000 stars by their spectra. ${ }^{36}$ She also

aided in equally important observations made by her female colleagues, who were more affectionately and respectfully known as: the Harvard Computers.

\footnotetext{
${ }^{36}$ Novae, plural for nova, are stars that suddenly become brighter and then fade slowly to their original state Matt Williams defines nebulae as not only massive clouds of dust, hydrogen and helium gas, and plasma; they are also often "stellar nurseries" - i.e. the place where stars are born. And for centuries, distant galaxies were often mistaken for these massive clouds."
} 


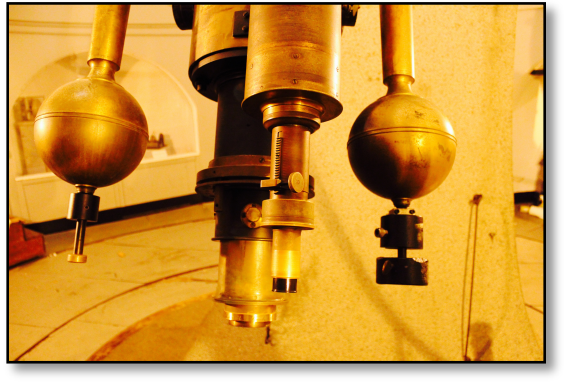

Figure 18: The Great Refractor at $\mathrm{HCO}$

\section{Chapter Eight}

\section{A Field Trip}

Let's say you're around the age of ten or eleven.

The best field trip ever might be to a real, live

observatory where you'd learn about the sun, stars, and space. If you grew up before juice boxes and handy pre-packaged snacks, you'd get a can of soda, possibly orange, frozen in the morning and wrapped in tin foil to keep it cold. The yellow school bus would deliver a teeming gaggle of not-yet-too-cool kids to the Harvard-Smithsonian Center for Astrophysics. You and your friends aren't old enough to be frightened by the enormity of something bearing such a name. Besides, you're super excited because you're going to get to look through a telescope and see cool sciency-type stuff.

In the early 90s the Smithsonian filmed an excursion just like the one I'm describing; watching it is like traveling back in time. The clothing and lunches may be different, but the openness to knowledge and the sense of adventure from leaving the daily rut of a classroom is tangible in Annie and the Many Colors of the Stars.

The film follows a group of sixth graders as they learn about astronomer Annie Jump Cannon, who worked at the observatory from 1896 to 1940. Annie did the lion's share of the work putting together the Henry Draper Catalogue, and served as the third curator of the plate collection after Henrietta. 
The camera zooms in on the flickering light of a glowing candle; there are 60 children present, but you only hear their voices. A girl says, "I saw a beautiful rainbow at a fountain, and there was, like, all these beautiful colors." Pudgy fingers hold long, dangly crystals, the sort that hang from chandeliers; they move them near the flames. "The most beautiful rainbow I ever saw was in the supermarket parking lot," a boy says, to the giggles of the other children.

The camera pans out as Harvard historian, Barbara Welther, tells the students about how Annie used to play with crystals just like these when she was young, and shows them how to make rainbows with their crystals to collective oohs and aahs followed by random declarations, "I see blue" and "Really? I see red!"

Before learning more about Annie and her work, the class spreads out on the lawn under a tree outside with their notebooks. They write and share questions, questions about the things they hope to learn when they visit the archives where they will see her diaries, scrapbooks, photographs and letters.

"What age did she get interested in stars?"

"How many friends did Annie Cannon have?"

One young girl in a bright pink t-shirt and a ponytail that seems to have migrated slowly west with the sun asks with an alarming degree of earnestness, "Was she ever deeply in love?" 


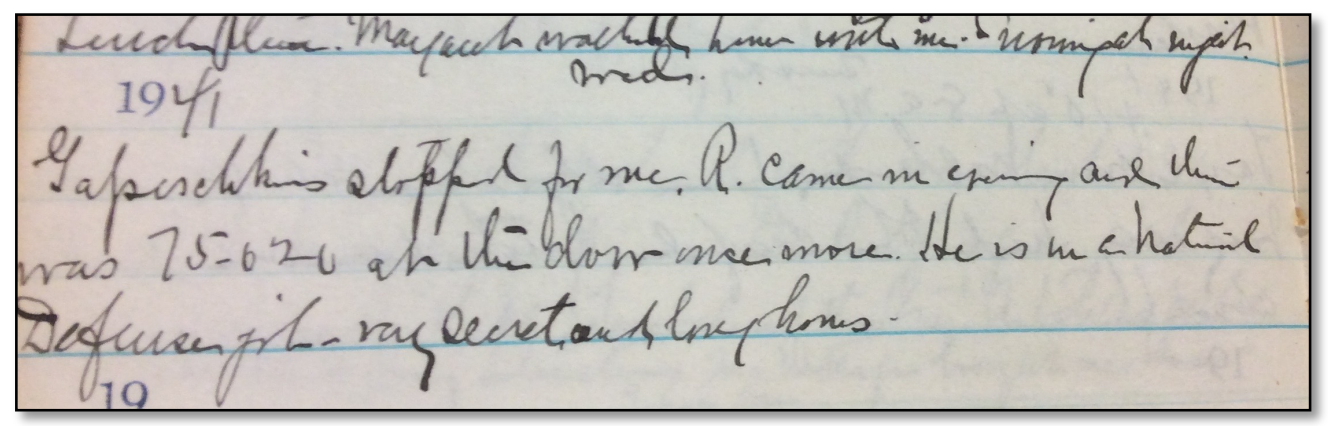

Figure 19: A photograph of Annie Jump Cannon's daily diaries, Harvard Archives

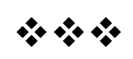

The students build spectrascopes and line up along the railing at the top of

the stairs outside of building D, looking up at the sky like hungry baby birds. ${ }^{37}$ They

are lead by Fiona Hughes McDonnell, a former high school science teacher who has

just started her graduate work at Harvard. She explains how astronomers looked at

stars and the sun with prisms and spectrascopes slightly stronger than their

handmade ones. The tool causes the light from these objects to spread out, allowing

astronomers to see the same rainbow of colors that the children see. The rainbow is

called a spectrum, and this is what Annie and the computers were looking at when

they were classifying the stars.

${ }^{37}$ A homemade spectrascope can be constructed with a shoebox, utility knife, pencil, ruler, rubber bands, and tape. You will need to order a diffraction grating online, but inexpensive ones are easily found. A diffraction grating is a little optical device that splits and diffracts light; on the diffraction grating "very fine and evenly spaced lines are ruled. These grooves use the wave properties of lighteach color a different wavelength - to break light into a spectrum. Measure and cut a rectangular hole on one end of the box; the hole should be $3 / 4$ of an inch by $1 \frac{1 / 2}{2}$ inches - roughly the same size as your diffraction grating slide. Cut a hole, the same size and orientation, in the other end of your box. Use the rubber bands to secure the box lid. Tape the diffraction grating over one hole, and voila. Have fun, but don't slice off a finger with the utility knife, and don't look directly at the sun without proper guidance. Hold your spectrascope up to a light source, making sure the holes are vertically oriented; you should see a rainbow extending right and left from the center. If you look at different light sources, you will see different configurations with darker bands of color depending on whether you are looking at a fluorescent light, a candle, or an incandescent bulb. 
Fiona tells the students to pay attention to the tiny dark lines in the rainbows, each as thin as a strand of hair as she teaches them how to document observations, "You can write down what you saw in any words you want. Okay?" A towheaded student opens her notebook and reveals colored vertical lines not the doodles of a young girl in the margins, but the beginning of scientific exploration with the object, time, and direction all clearly listed beneath her rainbows.

The tiny, darker lines in those bands of colors are like fingerprints; each element in the universe has a unique spectrum that can be used for identification. The student identifies the presence of hydrogen, oxygen, and helium in her notations using a scale that shows where the dark lines appear in the rainbow depending on what you are looking at. In the spectrascope, there are numbers running along the bottom like a ruler. Those numbers correlate to wavelength in nanometers; at 550 nanometers, a band would sit squarely between green and yellow. Helium and every other element will have always the same configuration of dark bands appearing in the same place along their unique spectra.

This young girl looks at the sun and finds these three elements by matching where the dark bands fell, and she draws them in her notebook with Crayola colored pencils.

From here, astrophysicist Robert Noyes, let the students look at slightly higher tech version of their spectroscopes. They gather around the machine and take turns looking into a hole at one end of the long rectangular device.

"Do you see the colors and the lights?" he asks. 
"The lines are going up and down; those are from the different elements."

The next boy gets excited, "Oh, look at that - there are all the colors!"

"Isn't that neat?" says a girl with a black headband. She bounces on the balls of her feet, eager to share her excitement with the person following her at the machine.

"So, all those lines are from different elements in the sun," the astrophysicist explains. "By measuring them we can figure out how much of the various chemical elements are in the sun and how hot the various pieces of the sun are."

To capture the spectra on the photographic plates Annie and her colleagues used, they attached prisms to the telescopes and took pictures. The resulting image, instead of looking like stars, contains many tiny little rectangles of grey lines, like confetti spread out on the glass.

In the next scene, the students sit and stand around a large square table in an ordinary looking conference room; each group has been given seven strips of paper with different spectra in black and white. They discuss and move their slips around and try to figure in which order the differing elements should be placed. Quietly, and one by one, the groups order them based on the number of bands visible in the spectrum with the smallest number of bands being placed on top. They learn how Annie's predecessors looked at the spectra and organized them, by similarities, into 22 different classes. Then, Annie came along and simplified the classification to seven. Subsequent generations of astronomy students might learn of Annie when 
they use her mnemonic Oh, Be A Fine Girl - Kiss Me to determine in which class a 64 star belongs: $\mathrm{O}, \mathrm{B}, \mathrm{A}, \mathrm{F}, \mathrm{G}, \mathrm{K}$, or $\mathrm{M}$.

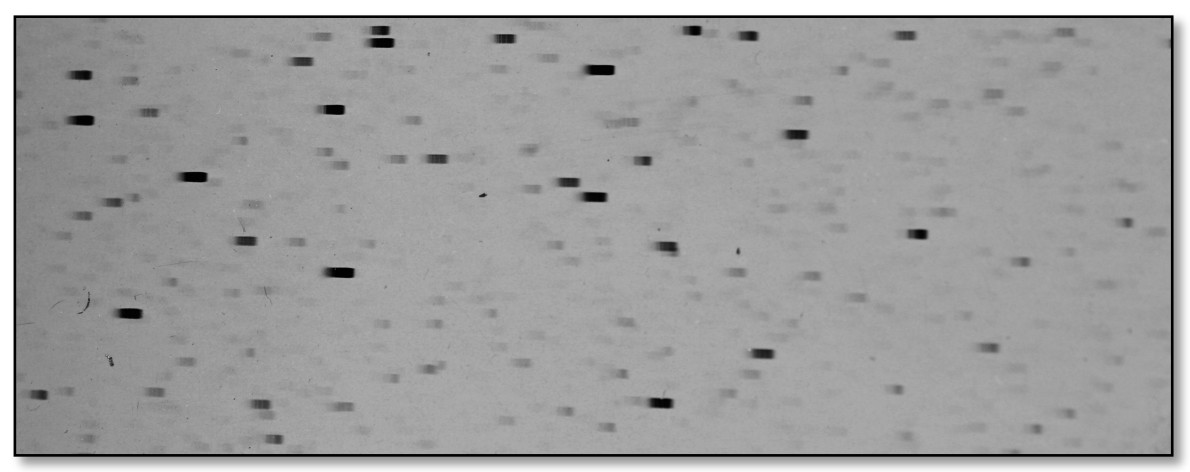

Figure 20: A photograph of a plate with stellar spectra at HCO

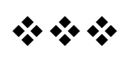

When the children sort the strips of paper with the black and white spectra, they see how she sorted the stars based on decreasing surface temperature. She would look at the spectra captured on the glass plates and call out the star's number, its classification, and intensity. A recorder would write down the information, and Annie would move on to the next. Working in this way she would classify hundreds of stars an hour. Once all the data was collected, the stars were added to the Henry Draper Catalogue.

The students also get to know a woman who persisted in the face of health problems to get her education. Annie lost most of her hearing after contracting scarlet fever during her undergraduate studies at Wellesley; studies she completed in 1884 in spite of this illness. When she was especially engrossed in her observations, Annie was known to turn off her hearing aid in order to focus. By most 
accounts, she was able to classify three stars a minute based on their spectra;

ultimately she classified more stars than anyone $-225,000$.

Unlike the majority of the Harvard Computers, who had no college education, Annie earned a masters degree, also from Wellesley, in 1907, while working at Harvard's observatory. The degree was only awarded after Pickering convinced administrators (who were reluctant to allow credits to be given to a paid employee) that Annie more than deserved this degree. Eventually, Annie would receive honorary doctorates from her home state's University of Delaware as well as University of Groningen, Wellesley, and Oxford. She was the first woman to receive this distinction from Oxford.

Between Annie's time at Harvard and the 90s when this field trip was filmed, progress marched on, but perhaps not as quickly as one might have hoped. The Smithsonian film was part of a larger project that explored interdisciplinary approaches to engaging students. Fiona, the instructor in the video, had seen her female students scoring at the top of her high school physics classes, but refusing to continue on with science studies beyond the requirements because they felt as if they did not belong. Looking back, Fiona explains that the standard teaching methods were what she described as "a rite of passage for a select few - a very particular type of male student." It was widely believed that boys were just better at science. ${ }^{38}$ Fiona left high school teaching for graduate school, hoping to find new ways of teaching and training teachers that both engages the students and changes

\footnotetext{
38 The saga of Harvard presidents resisting the tides of change continues. In 2005, twelve years after the film was made, Harvard President Larry Summers created quite a ruckus when he declared that men performed better at math and science because of genetics; he also denied discrimination and bias as the root cause for disparities in the number of women entering into these fields.
} 
who has access to ideas and knowledge by breaking down barriers that result from bias.

By the end of Annie and the Many Colors of the Stars, the students have learned these details about Annie's life and her contributions to astronomy. And, they got to experience, firsthand, the ways knowledge can be acquired. Maybe one of those young students is a historian or astronomer today, 26 years after their field trip adventure brought them to Harvard. During Annie's 40 years at Harvard, she won many awards and became quite famous for her work at the observatory. Today, the American Astronomical Society awards an annual Annie Jump Cannon Prize to a woman who has excelled in her research and shows great potential; Cecilia was the first woman to receive this prize in 1934. 


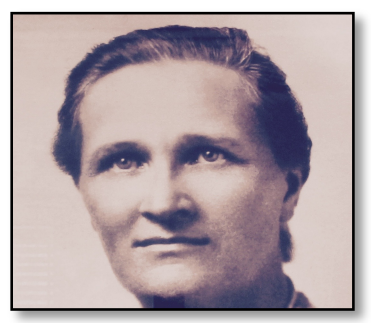

Figure 21: A photograph of a picture of Cecilia Payne at HCO

\section{Chapter Nine}

\section{A Star is Born}

Annie wrote, "by thus delving into the heart of the universe, some of our curiosity may be satisfied about the constitution and the nature of the distant orbs whose light has been travelling thousands of years to tell their story upon our magical films." But what story can a star tell?

About her early days at Harvard, Cecilia wrote, "Nothing seemed impossible in those early years; we were going to understand everything tomorrow." Shapley had taken Pickering's place as director and set out with an ambitious plan to transform the observatory into a grand research and teaching institution. Pickering had focused on data collection, but Shapley saw that astronomy was changing in exciting ways. Cecilia used to joke with her friend Adelaide Ames about the director, whom they nicknamed the D.D. for Dear Director, writing, "It used to be a dear little Observatory and he is going to make it into a Great Institution."

No longer interested in just cataloging and measuring distances, theoretical astrophysics was emerging as astronomers sought to make sense of phenomena only previously observed. How could chemistry and physics explain what scientists were seeing? How big is the universe and what is our place in it? What could a new understanding of atomic structure reveal about the life and death of stars? This shift away from just observing and measuring meant that the questions of science could 
be applied on an infinite scale. Cecilia wrote, "Temperature, density, velocity

could be studied over ranges unknown, untouchable on Earth."39

By studying stellar spectra and variable stars, Pickering had planted the seeds for discovery, but this new branch of science would find the answers. Thanks to the work of Williamina, Henrietta, Antonia, and Annie, the stars had been classified, but they didn't yet know exactly what they were classifying. Cecilia came along at exactly the right moment, with the right educational background to try and piece together the answers to this particular question.

Before she left England, her colleague E.A. Milne suggested a possible course of study for Cecilia in the states. He and Ralph Fowler had been focused on stellar structures, and were looking at the work of an Indian astrophysicist, Meghnad Saha. In the early 20 s, Saha was studying how the ionization of an element related to temperature and pressure; ${ }^{40}$ his research opened up the floodgates as scientists like Milne, Fowler, and the famed Henry Norris Russell ${ }^{41}$ were eager to understand the implications and apply the knowledge to their own research. As Cecilia described it,

\footnotetext{
${ }^{39}$ The Earth is 93 million miles from the Sun. Distances are so great, so incomprehensible to most of us, that 93 million miles equals one astronomical unit or A.U. Even this simplification is not enough to encompass the vast expanse of the cosmos. In the vacuum of space, a light year is the distance light travels in one year, just shy of six trillion miles. Unfortunately, beginning your calculations with $5.87849981 \times 10^{12}$ miles or even a simpler 63,240 A.U. is just plain unwieldy. Even more complicated geometry reduces 3.26 light years to one parsec. This knowledge could really come in handy if you are ever hanging around a Star Trek discussion board and want to discuss the location of USS Enterprise at any given time - in The Trouble with Tribbles, the Enterprise traveled "one parsec from a Klingon outpost," which Chekov thought might be "close enough to smell them"!

${ }^{40}$ Ionization occurs when an element loses or gains an electron, changing its charge; it is a chemical reaction that is the result of exposure to high temperature and/or pressure, "electrical discharge, particle collisions, or radiation."

${ }^{41}$ Henry Norris Russell was Harlow Shapley's mentor and a very important astronomer at the time. He was the director of Princeton's observatory from 1912-1947.
} 
Saha "applied the principles of physical chemistry to the ionization of stellar material, the idea that gave birth to modern astrophysics."

Saha's ionization theory held the potential to explain what the Harvard Computers had observed in the stellar spectra. Milne advised Cecilia to use the resources of Harvard's observatory to test and verify Saha's work. When Cecilia proposed this line of research to Shapley, he was pleased. Russell had been Shapley's thesis advisor and mentor. The two were very close; if Russell wanted the research done, Shapley was going to make it happen.

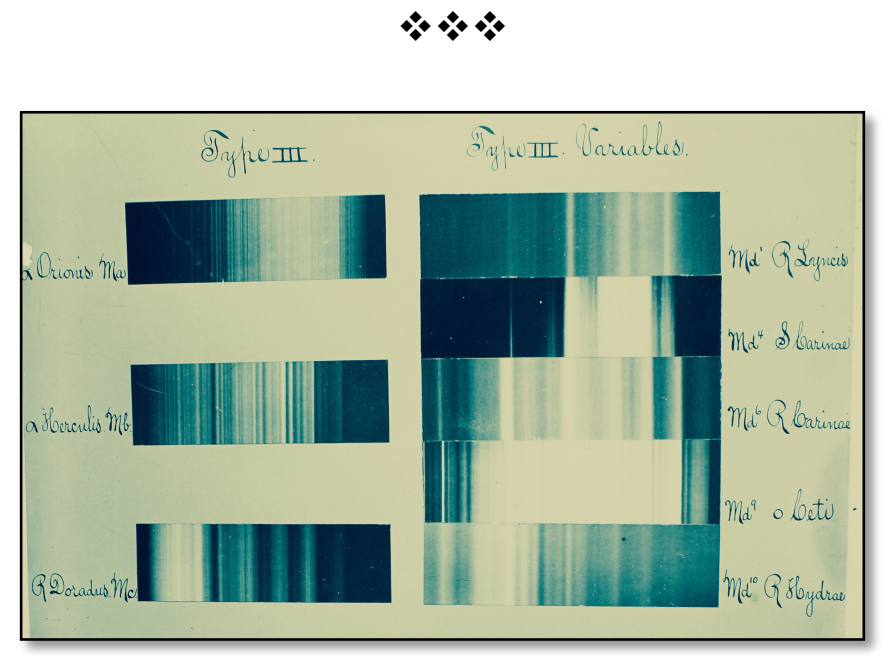

Figure 22: A photograph of a plate with magnified stellar spectra at $\mathrm{HCO}$

In the beginning: there was energy. And, then there was hydrogen.

Today, we know that stars are made of the lightest elements in the universe helium and hydrogen. Gravity exerts tremendous pressure on these elements, generating great heat, millions of degrees, in the interior of the star. As gravity compresses the hydrogen at this high temperature, the element's nuclei fuses and it is transformed into helium nuclei. This nuclear reaction is the source of a star's bright light. 
The power of this reaction, as well as a star's life span and luminosity, depends on the mass of the star. A smaller star has less fuel and will burn more slowly; it will live longer, but it will shine less brightly than a larger star. Astronomer Steven Soter explains, "A star like the Sun has a lifespan of about 10 billion years. A star half as massive will live about twenty times longer, while a star three times as massive will only live one-twentieth as long as the sun."

During the stable years of an ordinary star's existence, hydrogen nuclei are fused over and over again like little animated atoms marching into a furnace. But, when the star begins to exhaust this hydrogen supply, the nuclear forces pushing out no longer balance the gravitational forces pushing in, and things fall out of kilter. The star begins to collapse.

This is where Russell made what many believe is his greatest contribution to astronomy. Around 1910, working with Danish astronomer Ejnar Hertzsprung, the two devised a system that explained how stars evolve, depending on their initial mass. When a large star exhausts the hydrogen supply in the core, it begins to consume hydrogen in the area just outside the core. As helium fuses with more hydrogen, carbon and oxygen are created. As Soter writes, "By tapping these new sources of nuclear energy, the star heats up again and puffs up its outer layers." Now the star is a red giant. Inside this giant, at its core, a white dwarf star continues to burn while the giant puts out " expanding shells of gas. The hot white dwarf illuminates the shells with ultraviolet light, making them fluoresce in brilliant colors." 


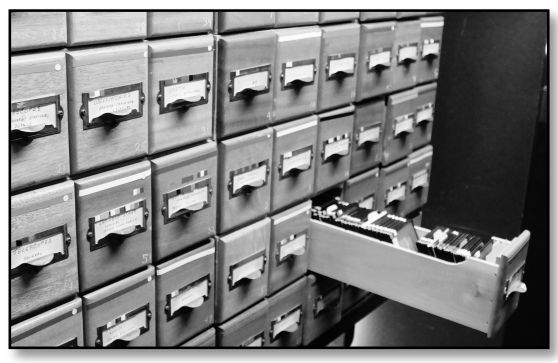

Figure 23: Slide catalogue at HCO

As knowledge and information accumulated, a clearer picture of stars and their atmospheres was beginning to take shape. While Hertzsprung and Russell discovered giants and dwarves, it would be several years before all the puzzle pieces would fit into place; this work was integral to the evolution of our understanding of the stars. In the mean time, the discovery revealed something important. Cecilia wrote, "then came disquieting reflections. Stars are not all alike."

So, she hit the books.

She read everything she could get her hands on - articles, observatory publications, books, and Harvard annals. Then, she moved onto the plate collection and studied the data in order to see what conclusions could be drawn. Days rolled into evenings and late nights; she often worked to the point of exhaustion. "I heard that Miss Leavitt's lamp was still to be seen burning in the night, that her spirit still haunted the plate stacks," she wrote. "I suspect that some credulous soul ... had seen me from afar, burning the midnight oil. Shapley had given me the desk at which she used to work."

Shapley was eager to publish results, but she demurred. She had not solved the problem yet. To Cecilia, publishing her unsolved problem would be an admission of failure, something she couldn't bear to do. 

Harvard to begin working on exactly the same problem on which Cecilia had set her sights. Shapley found himself in quite a predicament, which he resolved by pointing Menzel toward the cooler stars and Cecilia the hotter. Rather than partner the two, Shapley seemed to think, at least in Cecilia's mind, that people worked better under some level of duress - so, he kept the two separate and, perhaps, fanned the flames of competition a bit. She wrote that he felt pushing people to the brink of nervous breakdown was part of the process of earning a doctorate.

Years later she reflected on her envy with regret, "I have come to know that a problem does not belong to me, or to my team, or to my Observatory, or to my country; it belongs to the world."

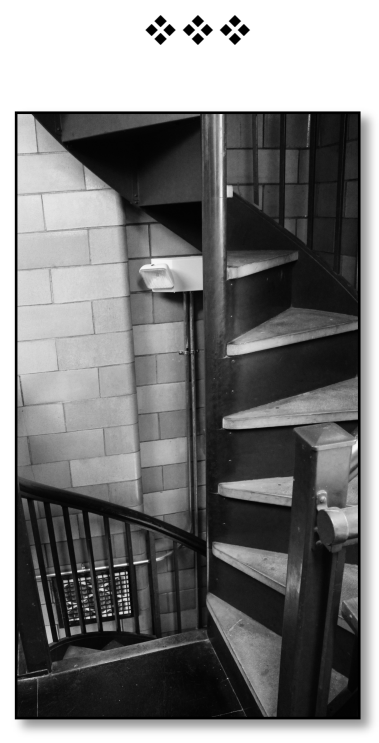

Figure 24: Spiral stairs in the platestacks at HCO

After haunting the observatory at all hours for two years, she began to see a relationship between temperature and the abundance of the elements. "Two years of daily contact with stellar spectra had brought one idea to the front. The 
composition of the stars was amazingly uniform," she wrote. Cecilia found an

abundance of hydrogen and helium, something her peers and colleagues discounted. She checked and rechecked her calculations, but each time she found the same thing: lots of hydrogen and helium.

She wrote Stellar Atmospheres: A Contribution to the Observational Study of Matter at High Temperatures in six weeks. Originally titled just Stellar Atmospheres, she added the subtitle in an attempt to stake her claim on area of study covered by an award being offered at Cambridge, the Adams Prize. She was not eligible to win the award, she suspected, because she was a woman. "But I said to myself, 'At least I am going to make a contribution to the subject,'” she declared.

To say the text was well received would be a bit of an understatement. While she was forced to conclude that her findings were "almost certainly not real," the consensus was that Cecilia had produced an epic work. Russell wrote to Shapley saying that it was the best dissertation he had ever read (excluding Shapley's, of course) and that her work "ought to be strongly recommended, not only to observatory libraries, but to all students of the subject."

It would be several years before Russell acknowledged that her data was correct and there was, indeed, an abundance of hydrogen and helium. At that time, the universe was thought to be relatively homogenous. If the Earth was made up largely of iron, then shouldn't other celestial bodies be made of the same stuff in the same or similar proportions? Being young and just getting started in her field, Cecilia yielded to the critiques. She wrote that hydrogen and helium abundances must be some sort of abnormality yet to be explained. 
What is more interesting about her dissertation is that the calculations she 74 performed to examine temperature and atomic abundances ultimately transformed a problem that had been plaguing astronomers for years. Owen Gingerich writes, "Throughout the nineteenth century, the temperatures of stars was seen as the central unsolved astrophysical problem." Previous efforts had gauged the sun somewhere between 6500 and 12000 degrees Celsius. Later work corrected that gap to between 5860 and 6260 degrees, but the problem was not going away - until Cecilia got her hands on it. Gingerich adds, "Her solution was so ingenious and satisfactory that it essentially turned the temperature problem into a non-problem." Many today credit Cecilia with discovering the composition of the stars. That may or may not be the case as there were so many noteworthy astronomers working on this question. The nature of science and research is one of cumulative efforts and incremental progress. And while Russell received the credit for this discovery at the time, he was a big fan of Cecilia's work. When asked who should be groomed as his replacement at Princeton, Russell replied that the ideal replacement "alas, is a woman!, -- not at present on our staff." 


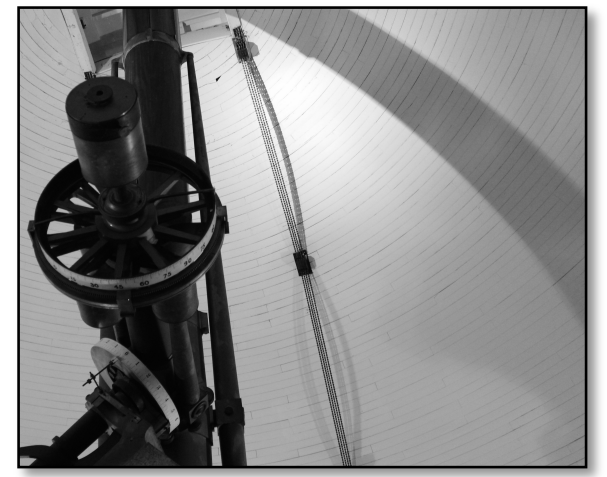

Figure 25: The Great Refractor at $\mathrm{HCO}$

\section{Chapter Ten}

\section{Eddington's Cup}

Life and work marched on at a steady pace in the decade that followed Cecilia's arrival in America. She continued to do what she loved; "The individual stars were her friends, and so were the spectral lines. She probably knew most of them by memory," writes Gingerich. Cecilia's fellowships were renewed - and while she was grossly underpaid, life at Harvard had benefits.

Some female astronomers took teaching positions at smaller universities, but that path typically came with heavy teaching loads, shoddy equipment, and minimal interaction with peers. The astronomy departments at these schools were much smaller than at the larger research institutions like Harvard and Mount Wilson in southern California. In most observatories, women were relegated to astronomical grunt work like the "computing" performed by Williamina's underlings in the previous century. If a woman was granted access to more heady projects, it wasn't unheard of for a male superior to take credit for a woman's work. Although Shapley measured projects in "girl hours," he was, in fact, quite generous about attributing successes to the individuals who labored for them.

At Harvard, it was assumed that Cecilia would be Annie's successor as the curator of the plate collection and overseer of large research projects. And, she 
could continue to work even if she were to get married; many places would not hire married women as it was thought that marriage and motherhood should take precedence over all other things.

In other words, astronomical work outside of Harvard could have been a slow agonizing death for someone like Cecilia who had found her spot on the frontlines of research and discovery.

That is not to say that staying at Harvard didn't come with its own set of problems. As an actual astronomy department began to emerge, she lectured and supervised graduate students, but was not listed in the catalogues or granted the title of professor; she was paid as a staff member with no corporation appointment at $\$ 2100$ per year. Male astronomers, some of whom were younger than her, were being hired starting at $\$ 3000$ and receiving substantial raises and promotions to assistant and full professorships in just a few years. When Menzel was brought back to Harvard as assistant professor in 1932 , he was offered $\$ 4500$ - the two were graduate students together and he made more than double what she earned. There was little reason for her to expect change as Harvard President A. L. Lowell told Shapley unequivocally, "Miss Payne should never have a position in the university while he was alive."

But, as an astronomer, it didn't hurt that she was becoming quite well known for her contributions to the field and she was winning awards, including Radcliffe's prize for the best original work. Cecilia felt she worked and socialized among equals and never believed that a fellow scientist viewed her as inferior because of her sex. 
"How we argued, how we walked about the streets and sat talking in restaurants 77 until the manager turned off the lights in despair!" she wrote. "We met as equals."

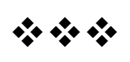

Just before completing her doctorate, she traveled to Toronto to attend the British Association for the Advancement of Science and Eddington came to hear her present a paper on her work, an honor that she did not take lightly. Cecilia wrote to her friend Margaret Harwood describing a group excursion to see Niagara Falls. Having slipped away from the crowd of gathered astronomers, she stood in silence soaking in the beauty of all that surrounded her. The sound was deafening; she let it envelop her. "I turned around and found the only other person in the world whom I should have liked to be there, standing beside me."

It was Eddington. ${ }^{42}$

Being an astronomer in this era was quite fun. There were only about 500 astronomers registered in the American Astronomical Society (AAS) at the time, so everyone knew each other. A steady calendar of meetings and conferences kept people on the go, and AAS meetings, in particular, were known to be spectacular. In 1926, astronomers were taken by ferry to Nantucket for day of dining, tours, swimming, sailing, and all manner of fun.

And, Harvard was one of the places to be. The most famous astronomers of the day came to the observatory to examine the plates, conduct research, and

\footnotetext{
42 There is little doubt as to the nature of Cecilia's feelings for Arthur Eddington, but he was a lifelong bachelor.
} 
lecture. She found herself in a very collegial environment with parties, dances,

and even an observatory philharmonic, which she once conducted. ${ }^{43}$ Shapley's parties were famous even if attendance was mandatory. She wrote, "Social events in the Director's residence embraced the whole staff from top to bottom, and invitations were treated as commands of royalty, under no circumstances to be refused." Dining, dancing, bridge, and charades helped the observatory family while away the hours. You could almost see her smiling as she wrote in her autobiography, some forty years later, about Shapley pantomiming Napoleon and Russell enacting a Greek tragedy swathed in a sheet. ${ }^{44}$

On New Year's Eve in 1929, the staff performed an adaptation of a Gilbert and Sullivan musical, the HCO Pinafore and Cecilia was cast as the heroine Josephine. The first act opens with a chorus of women singing:

$$
\begin{aligned}
& \text { We work from morn 'till night, } \\
& \text { for computing is our duty; } \\
& \text { We're faithful and polite, } \\
& \text { And our record book's a beauty." }
\end{aligned}
$$

Now that Cecilia was observatory staff, she was free to leave the dormitories and she got an apartment on Mt. Auburn with Francis Wright. The two young

\footnotetext{
43 Cecilia loved music and studied with Gustav Holtz in her high school years; she wrote that if it weren't for her love of science she would have pursued a musical life. Holtz is best known for his orchestra suite The Planets, which he composed between 1914 and 1916 while Cecilia was his student; the composition is surprisingly familiar to modern audiences, as it has been used in over 71 film soundtracks.

44 Russell was a serious astronomer, but not the liveliest of fellows; Cecilia mentions that he was known to have actually fallen asleep during at least one of his own lectures.
} 
women enjoyed entertaining visiting scholars and Cecilia turned out to be a great 79 cook. Francis said, "She could make the best soup out of almost nothing ... she understood flavors." But apparently she preferred cooking to cleaning, as the former exercised the mind; the latter did not.

Cecilia wrote that she felt drawn to nesting, to "feminine urges," and she seems to have thrived during this time. "When one is spending several years bringing a project to fruition, there is a great satisfaction in producing a masterpiece in the kitchen in a couple of hours," she wrote. ${ }^{45}$ Once thinking she lacked all feminine qualities, she came to understand that it wasn't femininity she had tried to reject, it was the notion of a woman's inferiority, which others mistakenly viewed through the lens of femininity, that she rejected.

Even Eddington joined them at their humble little abode. Francis remembered, "Sir Arthur Eddington was a brilliant conversationalist, and in our minds our best tea cup was tagged mentally with Sir Arthur's name."

After his visit, the teacup was and would remain Eddington's cup.

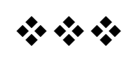

In 1930, Cecilia decided it was time to see the western observatories. Since she owned a car and Francis owned the camping gear, it seemed only logical that the two young women should venture out, across the dusty dirt roads between the east

\footnotetext{
45 Scientifically speaking, I can verify this claim based on my own penchant for baking and cooking under duress. My family recently toasted to my stress because it produced several noteworthy stews, macaroons, oatmeal cookies, and Cannelés Bordelais in one particularly harrowing two-week stretch of thesis writing.
} 
and west in her green Ford two-seater with tires too old for such a journey. Apparently, Cecilia was a bit of a miser, hoping to squeeze every last mile out of her tires; the women spent a fair amount of time dealing with flats in an era that predates service stations every few miles.

For Cecilia and Francis, it must have been a treat to sleep out under the stars and both women fondly recalled the trip in their later years. They even made an excursion to the bottom of the Grand Canyon; an old photo shows Cecilia looking surprisingly comfortable in Western attire, and sitting on a mule at the top of Bright Angel Trail.

While things weren't always perfect, these were very happy times at Harvard ... until Cecilia fell in love. There is nothing written about the source of her unrequited affections, only that she was despondent. She wrote, "I fell into a state of despair that seems to me now to have been comically Victorian. I felt that my life had been shattered, that I must make a break with the past."

It was time for Cecilia to go on another journey. 


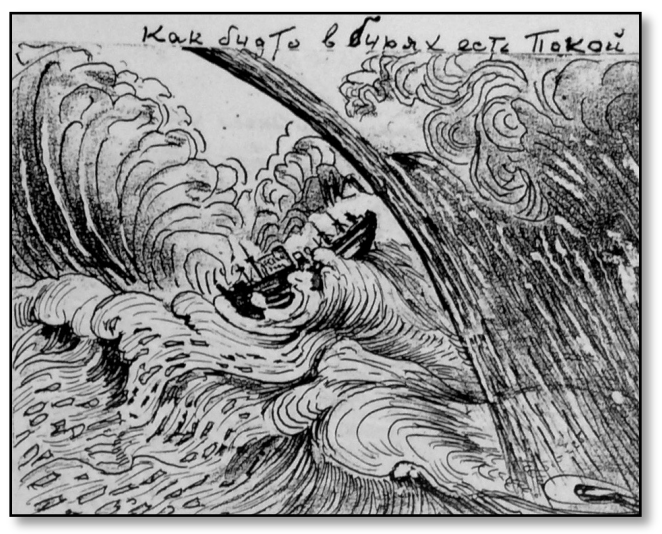

Figure 26: A photograph of Sergei's drawings

\section{Chapter Eleven}

\section{The Gaposchkins}

Cecilia left her mysterious heartbreak behind her and headed off to explore the observatories of Northern Europe. While attending a meeting, she met Sergei

Gaposchkin, a Russian astronomer from a poor fishing village, Yevpatoria, on the Black Sea in Crimea.

After World War I, civil war, social upheaval, and a series of misfortunes that almost ended with Sergei drowning at sea, he found himself on the shores of Turkey as the Bolsheviks solidified their power in Russia and drove out all who opposed them. Barred from returning to a fiancé and what little family had survived, Sergei settled in Germany. He earned a PhD, and took a position at the university, which he subsequently lost when Hitler rose to power. Sergei found himself a stateless man who could not return to the Soviet Union, as they would never trust a man who had lived and been educated in Germany.

Fearing he was about to be sent to the Sonneberg concentration camp after an interview with a Nazi official in 1932, he rode his bicycle to an astronomy meeting in Gottingen, hoping to find work outside of Germany. He looked for and found Cecilia and handed her a written statement explaining his situation.

Of their meeting, Cecilia didn't speak of love or attraction; she spoke of a sleepless night spent trying to figure out how to help "one who had resolved, as I 
had resolved, to be an astronomer, and against what terrible odds he had

achieved what had come so easily to me." After meeting her, Sergei described Cecilia as being "like a ripe peach left alone on the tree, darkened, wrinkled a little outside, but more delicious inside."

Cecilia returned to Harvard and waged a campaign to have him brought to the states. Harlow Shapley offered him a position as a research assistant, which he accepted in 1933. She wrote about her efforts to obtain work and a visa for him and concluded, "It led to the uniting of two lives, the flowing of two rivers, bound for the same goal, into one channel." That's it. She never mentioned her husband again, unless she referred to one of the many projects that they worked on together over the years as "The Gaposchkins."

\section{$\nLeftarrow *$}

When pressed for information about Cecilia's husband, Gingerich leaves it that the man was a bit eccentric; he is too polite, I think, to say more. Sergei's apparent eccentricities seem to have resulted in very little being written about him beyond allusions to his dramatic tendencies.

Yet, there was a listing for what I assumed was a textbook written by Sergei at the John G. Wolbach Library - Young For ever: the Story of Earth (sic). The librarian, Maria McEachern, invited me to use the library as much as I needed and promised to set his materials aside for me hinting obliquely that, "we do own several other self-published items by Sergei which are also quite...interesting." 
When I arrive at the library, she directs me to get comfortable and disappears into the netherworld behind the desk. I settle in on a nearby couch and start organizing my materials - iPad for photographing interesting pages, legal pad, pens, and laptop. With a startling thud, I'm pulled from my scholarly preparations as Maria drops three books, two of which are at least twice the size of a New York City phone book back when people still had a use for them. "Here you go," she says with a smile as she makes a hasty retreat.

I sit frozen - staring at (at least) 3000 pages of something quite ... interesting. The thickest volume has an aging, yellow cover with a drawing of a muscular man in a sailor's cap and speedo. There's typed text in both English and Russian, and large letters handwritten in calligraphy at the bottom of the cover read:

\section{SERGEI II}

RU-SS-IAN

The R in Sergei is situated between the legs of the scantily clad man. Somewhere around this fellow's right knee it says, "YOU CANNOT BE A SUPREME GENIUS WITHOUT BEING A SUPREME ATHLETE ALL YOUR LIFE” - with the period added at the end in black pen. I am looking at volume II of what I discover is his three-part memoir-slash-manifesto on how to live a long and healthy life as a genius.

I look up at Maria, who is standing behind the desk staring at me. She shrugs her shoulders and shakes her head, flashing a happy and knowing grin in my direction before returning to her own work.

Uncertain of exactly what to do with this little find, I pick up the thinnest book, Volume I, and slowly flip through the contents. Each page is the same jumbled 
mix of typed and handwritten English and Russian all voiced in third person: but 84 that, surprisingly, is not what is so "interesting" about these books. An extraordinarily large portion of each book contains pages of photos of the author in a speedo. Sergei pruning a tree from a ladder outside their home in Lexington, ${ }^{46}$ Sergei polishing the floors of their home ${ }^{47}$ with the caption, "At 80, with polishing the floors of his 16 rooms Castle on his own fours for 44 years he... maintained his Hercules-Apollo ..."; Sergei kicking a soccer ball, ${ }^{48}$ and Sergei doing a handstand on his front lawn. ${ }^{49}$ Each image also includes his age.

There are certain places in these odd volumes where a story emerges, but the thread generally disappears as quickly as it appeared. He writes of his birth in a poor Russian fishing village and his humble beginnings. This is juxtaposed against his telling of Cecilia's story, "she was born in the very heart of the English land and its Civilization." At some point, the prose becomes four line stanzas about their first home "of eight rooms / Colonial type with two floors." But the epic poem ends before it really began, as a page turn reveals black and white drawings, a collage of images: a woman's face, a geologic feature in Utah, ancient sailboats, the observatory at Mt. Wilson, and a man shaving with a straight razor.

The drawings are as lovely as they are confusing. I've stumbled on some sort of art brut, and I am quite certain I will never be able to make sense of any of it. His daughter Katherine speaks of Sergei's troubles and all that he experienced being a

\footnotetext{
46 In a speedo.

47 In a speedo.

48 In a speedo.

49 You guessed it... in a speedo.
} 
refugee for so many years; it isn't hard to imagine art and writing as a way of processing all he experienced.

Sergei was nothing short of effusive about his love for her throughout his volumes, "love by the beautiful lady Cecilia; the great man Sergei, given life." Of course, it wasn't always easy. Virginia Trimble writes that he mentions the names of other women throughout his memoir. ${ }^{50}$ And, their daughter Katherine describes him as behaving "flamboyantly" while her mother, ever the stoic, pretended not to know what was going on.

It isn't surprising to imagine Cecilia being tolerant of Sergei's eccentricities and foibles. For a woman who thought herself to be very unattractive, a woman who waited so long to find love, to find a partner so demonstrative of his affections must have brought her no small amount of joy - in spite of any difficulties the two may have had. Katherine wrote, "In truth, they loved each other deeply. Her last conscious thought was of him; without her, he was lost forever." In Sergei, Cecilia found a fellow scientist who would understand her passion for her work; she found a partner who would not only support her efforts, but also would make sacrifices so she could be the famous astronomer that she was born to be.

Over lunch in his office, I mention to Gingerich that I was just looking at Sergei's rather interesting manifesto, to which he replies, "You know she typed that thing for him?"

And that is all he will say on the matter.

\footnotetext{
50 He apparently gave Trimble a copy inscribed, "To lovely Virginia. In that first moment you were the (kindred) perfection Beauty and Kindness. For ever Yours Sergei, 1978."
} 


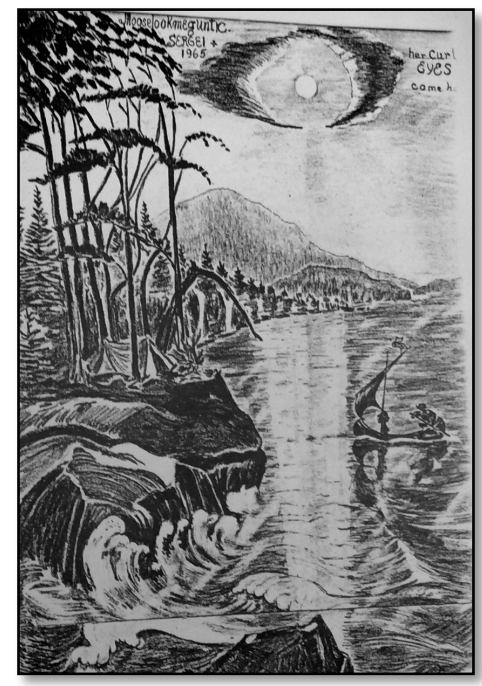

Figure 27: A photograph of Sergei's drawings

Cecilia and Sergei were married for forty-five years and had three children together - Edward, Katherine, and Peter. ${ }^{51}$ Cecilia's professional life competed, at times, with her family responsibilities, so he was frequently left to care for the children and household on his own. At work, the two collaborated on many projects together, most notably their efforts to catalog all known variable stars.

As the children got older, the observatory became a source of adventure. Katherine recalls getting bored at home and taking the train to Harvard with her brothers. There is window on the first floor of the plate stacks; it's located beneath the black wrought iron fire escape that runs up the side of the building, around the

\footnotetext{
51 The young couple bought a house in Lexington, and at the onset of WWII, purchased a poultry farm in order to contribute to the war effort. She wrote, "We had a double purpose: to contribute to the food supply, and to give work to a refugee family." Although they never found a family to run the farm, they raised chickens for eggs, and broilers for meat; turkeys were added as some point as well. Cecilia's English heritage was well represented on the farm in the form of a cow named Victoria, a pig named Albert, and a horse named Stanley -- "from a fancied resemblance to the Prime Minister," she wrote.
} 
corner to the left of the main entrance of Building D. Unlike typical windows that one raises and lowers, this window swings outward from the bottom and is large enough to be used for loading and unloading unwieldy materials in and out of the plate stacks. The children thought they were quite clever and sneaky using this window to get past the prying eyes of officious adults and make it to their father's office, which was near their covert entry point. "We would show up, and probably we weren't necessarily always welcome because kids in the research environment is not necessarily the best thing. But they were all very patient and very good about it," she said. Katherine was quite embarrassed to learn many years later that everyone knew about their furtive movements about the observatory.

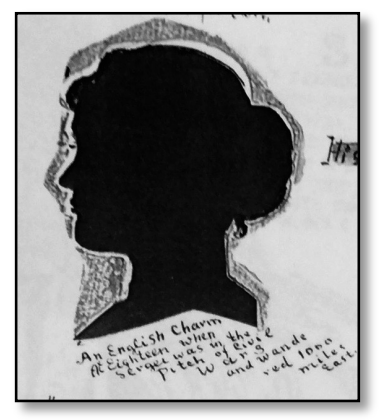

Figure 28: A photograph of Sergei's sketch of Cecilia's profile

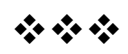

"Being a woman has been a great disadvantage," Cecilia wrote in retrospect. "It is a tale of low salary, lack of status, slow advancement. It has been a case of survival, not of the fittest, but of the most doggedly persistent."

Edwin Hubble once wrote that Cecilia was, in fact, "the best man at Harvard." But in her time at the university, she outlasted observatory directors, professors, research assistants and two university presidents before finally receiving her due - 
a substantial raise, a corporation appointment, and a stint as Harvard's first female department chair. In spite of all of her fame and accomplishments, this didn't happen until 1956; she retired from the university in $1965 . .^{52}$

When young women would ask Cecilia if they should pursue a career in science, she would advise them to do so only if they felt no other path would make them happy, because a life as a woman in the sciences would yield little in the way of tangible rewards. After her own long career in astronomy Virginia Trimble responded to Cecilia's advice, writing: "I have come to accept the wisdom of Cecilia's view that the only honorable form of affirmative action is in the context of 'encouraging young people to go into science' is to make sure that the obstacles look just as large to white males as to anyone else."

Both women were right, but thankfully times are changing.

Things are getting better, and there are a great number of people working to make sure the barriers are removed, because today most would agree that we actually might need women to be equally represented in the sciences.

\footnotetext{
52 While she retired from teaching, she never retired from her research at the observatory as she felt there was much more to study, right up until her death in 1979.
} 


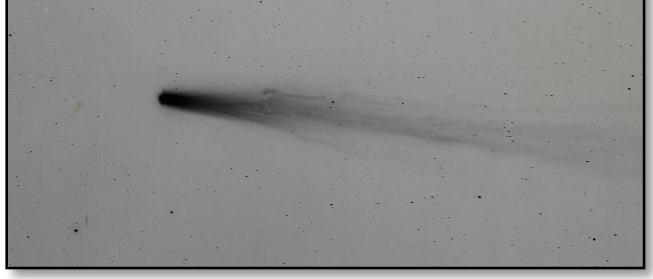

Figure 29: A photograph of a negative of Halley's Comet

\section{She Conquers Who Conquers Herself}

Janice Levenhagen-Seeley has trouble sleeping. She's the founder of ChickTech, and

she's also a wife and mother of two, although she looks too young for everything she's accomplished so far. Thin, with long light brown hair, and narrow dark glasses, she shows up for our meeting in jeans and a flower-print, zippered hoodie. After hellos that feel more like we've been friends for a long time than newly acquainted via email, she excuses herself to grab either coffee or an alcoholic drink - she can't decide which, she explains, because she is having a very bad day.

Janice is having a bad day because the organization that housed ChickTech's office closed without warning and she faced the logistical nightmare of gaining access to the now-defunct space, renting a truck, and recruiting volunteers to help move everything with only an hour's notice. Even though she's obviously frustrated, she laughs and smiles a lot, making her oddly relaxing to talk to given the subject matter.

Janice graduated from Oregon State University with a B.S. in computer engineering in 2006, where she was one of few women in her program - the engineering or hardware side of tech is even more male-dominated than the software side. During and after school, Janice believes she suffered from Imposter Syndrome, where no matter what evidence was presented, she didn't think she belonged. 
The feelings she shares are becoming a recurring refrain echoed by

women in STEM fields hoping to share their experiences as a way of bringing about change. ${ }^{53}$ Many describe being the only women in the room: every time you walk in to the class or raise your hand to ask a question or fumble with your words, you feel as if everyone is watching you. You feel you are a total failure and everyone knows it. 54

Janice remembers thinking she was at the bottom of the class even though she was working harder than she'd ever worked before; a professor pulled her aside and told her she was the only student getting A's; the others were getting C's.

She always felt as if everyone knew she was a fraud.

From there, her first forays out into the workforce were troubling. One major company held a spot for her for four months during a hiring freeze, but rescinded the offer when they found out she was pregnant. Another company told her that her maternity leave would be inconvenient for them, so they were going to go for someone else. She's animated when she explains, “I decided I didn't want to deal with it. I had my daughter; I stayed home for a year. I was pretty sure my brain was dying; it was a terrible feeling."

\footnotetext{
${ }^{53}$ In a recent article in the Daily Nebraskan, one female engineering major describes how "her professor said that all the girls in the class automatically started with a 100 percent average and that points would be docked as they completed assignments. In contrast, boys would begin with a ' $\mathrm{F}$ ' and have to work their way up." While the student thinks the professor was joking, she didn't like being singled out. Another female student expressed frustration about how her peers think she will easily land a job after graduation "simply as a diversity hire." She feels compelled to prove she is, as a woman, "capable of being an engineer."

${ }^{54}$ This issue is prevalent in most scientific disciplines, prompting one documentary filmmaker to launch the Bearded Lady Project in 2015. For the film, women paleontologists donned fake beards while working in the field and in the lab to "to educate the public on the inequities and prejudices that exist in the field of science." Proceeds from the film will go to a scholarship for girls interested in studying science.
} 
Motivated by these experiences, she decided to do something. Janice got her MBA from Willamette University and launched ChickTech in 2011.

ChickTech currently has six chapters in Oregon, Washington, California, Illinois, and New York. Two new ones are in the works in Texas and Massachusetts as well. Each year, the individual chapters recruit 100 girls from area high schools for a free two-day event in November, followed by monthly workshops through June, and then summer camps and local events in each city. The students are nominated by their teachers, and the teachers are asked to suggest girls who may possess an aptitude for tech, but have no prior experience. "This is a way for teachers to say, I don't really know that this student would be good with tech, but I know that they are a lot smarter than they are acting," she explains. "Maybe this will be the thing that gets them excited." In November of 2015, the organization's chapters collectively reached 600 girls at the big kickoff event, ChickTech High School. The Portland group held the weekend workshop in Portland State University's engineering building where the girls designed video games, made a movie, built robots, printed jewelry on 3D printers, and learned about website development.

Janice has taken on quite a bit. The expansion to other cities seems like a lot for an organization that has just reached the point of being able to deliver a full-time salary for her, thanks to a grant from the Adobe Foundation. There have been multiple challenges with funding. Many companies are hesitant to invest money in a program that may or may not deliver employees directly into their own ranks. "Most companies have a hard time thinking that far ahead," she explains. "Or even 
understanding the idea that if you support something your employees are supporting and show that you are a good employer, then that will help with attracting more diverse candidates, but they have this disconnect."

In response, she and her board are brainstorming a fee-based consulting arm of ChickTech that would provide a means of evaluating a company's cultural competency, as well as connecting companies looking for qualified women to qualified applicants.

Janice also hasn't been able to afford studies to track their progress, so there's no data to prove ChickTech actually works. That's not going to stop her; she believes flooding the workforce with young women will ultimately change things for the better.

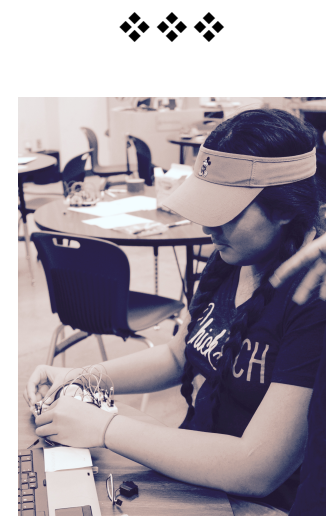

Figure 30: A student works on building a robot at ChickTech High School

On day two of ChickTech High School, I hop from workshop to workshop in order to see how students are faring. St. Mary's sophomore Maria and Grant High School sophomore Michaela are hunched over a laptop whispering. Neither girl plays video games in their free time, but they both signed up for a workshop on game design. "Mostly I like drawing the little characters," says Michaela with a big 
smile. Maria wears two long French braids, and is dressed in sports leggings, Adidas sneakers, and a denim jacket. Michaela is dressed similarly, with thick dark wavy hair brushed so that it floats more than hangs around her face. They both smile a lot in between lip biting and staring at the screen in front of them. They're totally engrossed in the work at hand.

The girls are creating a Christmas-themed video game where a penguin skates on an ice sheet to eat cupcakes and avoid snowballs, both of which are falling from the sky above. The program doesn't require writing code; it's a platform called Stencyl that allows them to drop and drag features while creating a logic-driven system for moving the cheerful little penguin to and fro. If: left cursor is down, move left. Otherwise if: right cursor is down, move right. Otherwise: stand still.

Both are eager to chat, but our conversation ebbs and flows in conjunction with what's happening on screen. "Oh, oh, look at that - it's moving!" one girl says while in the middle of telling me about her science interests, which seem rather loosely defined beyond a general sort of happy indifference directed at something that isn't immediate. Mary's favorite class is either Bio or Spanish; Michaela's is either Math or Arabic. After spending a little time with these teenagers, ${ }^{55}$ I am inclined to see a causal relationship between like and what-is-happening-in-themoment, meaning that Bio is great on a day when it is fun, and not so much on a day when it isn't.

In a digital design and user experience workshop, Addison, a sophomore at St. Mary's, works on developing a new website for a local nonprofit. Her group uses

\footnotetext{
${ }^{55}$ And helping raise one as well...
} 
a program that allows them to draw the pages on paper, take photos of them, and 94 then load them into a mockup of their site with clickable links, all without writing any code. On day one, they held staged meetings with folks from the nonprofits and learned about what was frustrating them about their existing websites in order to inform their redesign.

Addison's team of three hunches over a table discussing their options; they are completely engaged in their project. Consultation and decision-making is friendly. No one seems inclined to take over; when sharing ideas, everyone smiles and no one seems upset when her idea isn't selected. Another student at the table announces that she is taking two math classes this year because she wants to. I ask if they all like math. There are general nods of agreement around the table when Addison replies, "I started liking math when I started getting good at it."

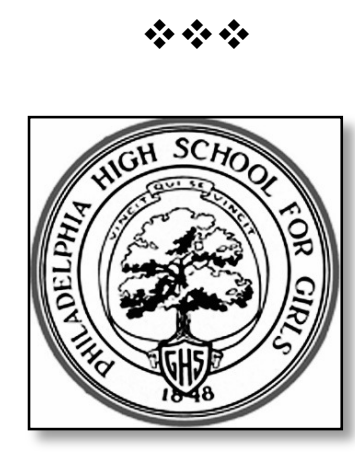

Figure 31: Philadelphia High School for Girls insignia

After the morning session, the girls line up along the hallway for photos, clad in black t-shirts emblazoned with the ChickTech logo. At the last minute, a volunteer decided to use the professional photographer who had volunteered his time for an impromptu photo shoot before lunch. They've made signs, which read, "I am the 
future." Each girl grabs a job title like bio/informatics engineer or graphic

designer, affixes it to the sign, and the photographer snaps her picture under a ChickTech sign. I suspect the girls aren't as interested in a career as a network administrator as they are in the tamales, chips, and salsa that await them when they've jumped through this midday hoop. But, that's okay, because these girls aren't supposed to know exactly who they want to be - yet. Eventually, when a student like Maria or Addison has matured a bit, she might say "I enjoy math and solving puzzles, and being an engineer would let me do that all the time."

I'm beginning to see that it isn't so much about convincing these girls that they love science or making them want to be an engineer, although that's possible too; it's about normalizing the idea that they can. And, when I look at these young women, who look just like I do in my own faded yearbook photos, I think again of my old high school motto: she conquers who conquers herself. Perhaps it isn't entirely fair to have to add conquering so many other things to the complex formula for figuring out one's future. Of course, with women like Moe, Alexis, Janice, and countless others laying awake at night trying to figure out how to change the world for them, it won't be easy, but maybe they have a fighting chance.

The thing that is so wonderful about all the women I've spent time with is their ordinariness. The teachers and young women at St. Mary's, the volunteers at ChickTech, the Harvard Computers, and Cecilia are all completely normal, gardenvariety humans who did and do great things every day. We seem to want the people who succeed to be heroic in some way, but maybe this is problematic. When we look at the lives of those who do stellar works and paint them as mythical heroines, then 
the rest of us mere mortals are left to wonder what we could possibly hope to achieve. Maybe some people end up thinking it is pointless to even try.

I see this with my stepdaughter, who seems to see the accomplishments of others as something beyond her capabilities. She sees successful people as being magically endowed with something unattainable and this sets their achievements apart from anything she could do. Young women could feel as if there is no place for them in these fields because they aren't special in some intangible way. If we can break down this wall of perception and reveal that the technology and scientific marvels of tomorrow are just waiting to be done by ordinary humans, maybe it won't seem such a daunting, insuperable task.

Cecilia and these women did the extraordinary. They accomplished great deeds in spite of the obstacles, but they were not different, because all things being equal, women aren't different. Women aren't special. Perhaps empowerment is saying there is no difference between you and those who've done great work except for the fact that they tried, and we did our best to get out of their way and let them. 
Abir Am, Pnina and Dorinda Outram, eds. Uneasy Careers and Intimate Lives: Women in Science, 1787-1979. New Brunswick, NJ: Rutgers University Press, 1987. American Association of University Women. Solving the Equation: Variables for Women's Success in Engineering and Computing. Washington DC: AAUQ. 2015. Print.

Boyd, Sylvia. Portrait of a Binary: The Lives of Cecilia Payne and Sergei Gaposchkin. Mass: Penobscot, 2014. Print.

Brown, Emma. “Obama outlines $\$ 4$ billion ‘Computer Science for All’ Education Plan." The Washington Post. 30 Jan 2016. Web. 30 Jan 2016. Retrieved from: https://www.washingtonpost.com/local/education/obama-outlines-4billion-computer-science-for-all-education-plan/2016/01/29/3ad40da2c6d9-11e5-9693-933a4d31bcc8_story.html

Buchen, Lizzie. "May 29, 1919: A Major Eclipse Relatively Speaking." Wired. Wired, 29 May, 2009. Web. 30 Sept 2015

Center for Astrophysics. Spectrosopy and the Birth of Astrophysics. American Institute of Physics, College Park, MD. Web. Retrieved from: https://www.aip.org/history/exhibits/cosmology/tools/toolsspectroscopy.htm

Comrie, L.J. to Shapley, H., March 7, 1923. H. Shapley Directorial Papers, Harvard University Archives. January 2016 
Constable, Marie. The Living Past: The Cavendish in 1932. University of Cambridge 98 CavMag. January 2010. Web. Retrieved from: http://www.phy.cam.ac.uk/alumni/files/cavmag-jan10.pdf da Cruz, Frank. L.J. Comrie. Columbia University Computing History. 17 April 2008. Web. 4 January 2016. Retrieved from: http://www.columbia.edu/cu/computinghistory/comrie.html Eddington, Arthur Stanley. Space, Time, and Gravitation; an Outline of the General Relativity Theory. New York: Harper, 1959. Print.

Ellis, Richard, Ferreira, Pedro, Massey, Richard \& Weszkalnys, Gisa. “90 Years On the 1919 Eclipse Expedition at Príncipe." Astronomy \& Geophysics. Astronomy \& Geophysics, 2009, 50(4) pp 4.12-4.15. Web. 30 Sept 2014

Fleming, Williamina Paton Stevens. Journal of Williamina Patton Fleming. 1900. Web. 19 Feb 2016.

Hamilton, Helen. The Compleat Schoolmarm: a Story of Promise \& Fulfilment. Oxford: B. H. Blackwell, 1917. Print.

Haramundanis, Katherine, ed. An Autobiography and Other Recollections. Great Britain: Cambridge University Press, 1996. Print. Interview of Cecilia Payne-Gaposchkin by Owen Gingerich on March 5, 1968 Niels Bohr Library \& Archives, American Institute of Physics, College Park, MD USA www.aip.org/history-programs/niels-bohr-library/oral-histories/4620 Interview of Harlow Shapley by Charles Weiner and Helen Wright on 1966 June 8, Niels Bohr Library \& Archives, American Institute of Physics, College Park, 
MD USA, www.aip.org/history-programs/niels-bohr-library/oral- 99 histories/4888-1

Interview of Harlow Shapley by Helen Wright and Charles Weiner on August 25, 1966. Niels Bohr Library \& Archives, American Institute of Physics, College Park, MD USA, www.aip.org/history-programs/niels-bohr-library/oralhistories/4888-2

Interview of Margaret Mayall by Owen Gingerich on August 11, 1986.

Niels Bohr Library \& Archives, American Institute of Physics, College Park, MD USA, www.aip.org/history-programs/niels-bohr-library/oral-histories/28323-1

"Ionization." Collins English Dictionary - Complete and Unabridged, 12th Edition 2014. Harper Collins. 25 Feb. 2016 http://www.thefreedictionary.com/ionization Johnson, George. "A Trip Back in Time and Space." The New York Times. 10 July 2007. Web. 20 January 2016.

Johnson, George. Miss Leavitt's Stars. New York: Norton, 2005. Print.

Lockard, Brett and Wolf, Michael. "Employment Outlook: 2010-2020" U.S. Bureau of Labor Statistics. Jan 2012. Web. 12 Nov 2015. http://www.bls.gov/opub/mlr/2012/01/art5full.pdf Mack, Pamela Etter. Women in Astronomy in the United States 1875-1920. 1977. Publications. Paper 7. http://tigerprints.clemson.edu/history_pubs/7 
Nelson, Sue. Williamina Fleming: Star of Scotland. Ada Lovelace Day. 13 October 100 2015. Web. Retrieved from: http://findingada.com/book/williaminafleming-star-of-scotland/

Philip, A.G, Davis and Koopman, Rebecca, eds. The Starry Universe: The Cecilia PayneGaposchkin Cententary. New York: Davis, 2000. Print.

Soter, Steven and deGrasse Tyson, Neil (eds). Cosmic Horizons: Astronomy at the Cutting Edge. New York: New Press, 2001. Print.

Wayman, Patrick A.. “Cecilia Payne Gaposchkin: Astronomer Extraordinaire.” Astronomy \& Geophysics, 34:1, pp. 1.28-1.29. Feb. 2002. Web. Jan 2016

Williams, Matt. Nebulae: What Are They And Where Do They Come From? Universe Today. 24 December 2015. Web. 21 February 2016.

Woolf, Virginia. A Room of One's Own. 1929. San Diego: Harcourt Brace Jovanovich, 1989. Print. 